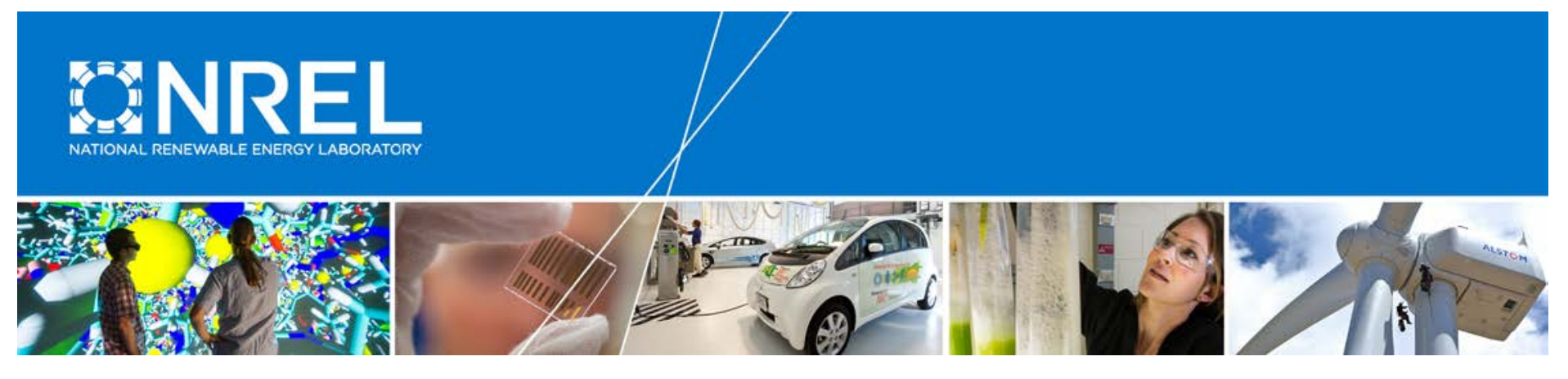

\title{
Variable Renewable Energy in Long-Term Planning Models: A Multi-Model Perspective
}

Wesley Cole, Bethany Frew, Trieu Mai, and Yinong Sun

National Renewable Energy Laboratory

John Bistline, Geoffrey Blanford, and David Young

Electric Power Research Institute

Cara Marcy and Chris Namovicz U.S. Energy Information Administration

Risa Edelman, Bill Meroney, Ryan Sims, and Jeb Stenhouse

U.S. Environmental Protection Agency

Paul Donohoo-Vallett

U.S. Department of Energy

NREL is a national laboratory of the U.S. Department of Energy Office of Energy Efficiency \& Renewable Energy Operated by the Alliance for Sustainable Energy, LLC

This report is available at no cost from the National Renewable Energy Laboratory (NREL) at www.nrel.gov/publications.

Technical Report

NREL/TP-6A20-70528

November 2017

Contract No. DE-AC36-08GO28308 


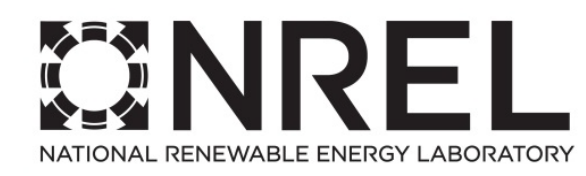

\title{
Variable Renewable Energy in Long-term Planning Models: A Multi-model Perspective
}

\author{
Wesley Cole, Bethany Frew, Trieu Mai, \\ and Yinong Sun \\ National Renewable Energy Laboratory \\ John Bistline, Geoffrey Blanford, \\ and David Young \\ Electric Power Research Institute
}

Cara Marcy and Chris Namovicz U.S. Energy Information Administration

Risa Edelman, Bill Meroney, Ryan Sims, and Jeb Stenhouse U.S. Environmental Protection Agency

Paul Donohoo-Vallett

U.S. Department of Energy

Prepared under Task No. OOSP.10291.17.02.25

National Renewable Energy Laboratory 15013 Denver West Parkway Golden, CO 80401

303-275-3000 • www.nrel.gov
NREL is a national laboratory of the U.S. Department of Energy Office of Energy Efficiency \& Renewable Energy Operated by the Alliance for Sustainable Energy, LLC

This report is available at no cost from the National Renewable Energy Laboratory (NREL) at www.nrel.gov/publications.

\section{Technical Report}

NREL/TP-6A20-70528

November 2017

Contract No. DE-AC36-08G028308 


\title{
NOTICE
}

This report was prepared as an account of work sponsored by an agency of the United States government. Neither the United States government nor any agency thereof, nor any of their employees, makes any warranty, express or implied, or assumes any legal liability or responsibility for the accuracy, completeness, or usefulness of any information, apparatus, product, or process disclosed, or represents that its use would not infringe privately owned rights. Reference herein to any specific commercial product, process, or service by trade name, trademark, manufacturer, or otherwise does not necessarily constitute or imply its endorsement, recommendation, or favoring by the United States government or any agency thereof. The views and opinions of authors expressed herein do not necessarily state or reflect those of the United States government or any agency thereof.

This report is available at no cost from the National Renewable Energy Laboratory (NREL) at www.nrel.gov/publications.

Available electronically at SciTech Connect http:/www.osti.gov/scitech

Available for a processing fee to U.S. Department of Energy and its contractors, in paper, from:

\author{
U.S. Department of Energy \\ Office of Scientific and Technical Information \\ P.O. Box 62 \\ Oak Ridge, TN 37831-0062 \\ OSTI http://www.osti.gov \\ Phone: 865.576.8401 \\ Fax: 865.576.5728 \\ Email: reports@osti.gov
}

Available for sale to the public, in paper, from:

\author{
U.S. Department of Commerce \\ National Technical Information Service \\ 5301 Shawnee Road \\ Alexandria, VA 22312 \\ NTIS http://www.ntis.gov \\ Phone: 800.553 .6847 or 703.605 .6000 \\ Fax: 703.605.6900 \\ Email: orders@ntis.gov
}




\section{Acknowledgments}

We gratefully acknowledge the many people whose efforts contributed to this report. The IPM, NEMS, ReEDS, and US-REGEN modeling teams all contributed to the overall model development and the discussion of ideas presented in this work. Steve Capanna (DOE) and David Hunter (EPRI) were instrumental in designing this project and in organizing the workshops. We are grateful to Evelyn Wright (Sustainable Energy Economics) and Jeff Logan (NREL) for providing feedback on this work. The work for this report was funded by the EERE Office of Strategic Programs, Solar Energy Technology Office, and Wind Energy Technology Office under contract number DE-AC36-08GO28308, and by the Environmental Protection Agency. The views and opinions expressed in this paper are those of the authors alone and do not necessarily reflect those of the U.S. Government, the Environmental Protection Agency, the Energy Information Administration, the National Renewable Energy Laboratory, or the Electric Power Research Institute, and no official endorsement should be inferred. 


\section{List of Acronyms}

$\begin{array}{ll}\text { AEO } & \text { Annual Energy Outlook } \\ \text { CEM } & \text { capacity expansion model } \\ \text { CSAPR } & \text { Cross-State Air Pollution Rule } \\ \text { CSP } & \text { concentrating solar power } \\ \text { CV } & \text { capacity value } \\ \text { EIA } & \text { U.S. Energy Information Administration } \\ \text { EMM } & \text { Electricity Market Module } \\ \text { EPA } & \text { Environmental Protection Agency } \\ \text { EPRI } & \text { Electric Power Research Institute } \\ \text { ERCOT } & \text { Electric Reliability Council of Texas } \\ \text { GW } & \text { gigawatt } \\ \text { HIVG } & \text { high variable generation } \\ \text { IPM } & \text { Integrated Planning Model } \\ \text { kW } & \text { kilowatt } \\ \text { LCOE } & \text { levelized cost of electricity } \\ \text { LDC } & \text { load duration curve } \\ \text { LP } & \text { linear program } \\ \text { MATS } & \text { Mercury and Air Toxics Standards } \\ \text { MW } & \text { megawatt } \\ \text { NEMS } & \text { National Energy Modeling System } \\ \text { NERC } & \text { North American Electric Reliability Corporation } \\ \text { NLDC } & \text { net load duration curve } \\ \text { NPV } & \text { net present value } \\ \text { O\&M } & \text { operation and maintenance } \\ \text { PV } & \text { photovoltaic } \\ \text { QCP } & \text { quadratically constrained program } \\ \text { R\&D } & \text { research and development } \\ \text { RE } & \text { renewable energy } \\ \text { ReEDS } & \text { Regional Energy Deployment System } \\ \text { RPS } & \text { renewable portfolio standard } \\ \text { TWh } & \text { terawatt-hours } \\ \text { US-REGEN } & \text { United States Regional Economy, Greenhouse Gas, and Energy } \\ \text { VRE } & \text { ariable renewable energy } \\ \text { WACC } & \end{array}$




\section{Executive Summary}

Long-term capacity expansion models of the U.S. electricity sector have long been used to inform electric sector stakeholders and decision makers. With the recent surge in variable renewable energy (VRE) generators - primarily wind and solar photovoltaics - the need to appropriately represent VRE generators in these long-term models has increased. VRE generators are especially difficult to represent for a variety of reasons, including their variability, uncertainty, and spatial diversity. To assess current best practices, share methods and data, and identify future research needs for VRE representation in capacity expansion models, four capacity expansion modeling teams from the Electric Power Research Institute, the U.S. Energy Information Administration, the U.S. Environmental Protection Agency, and the National Renewable Energy Laboratory conducted two workshops of VRE modeling for national-scale capacity expansion models. The workshops covered a wide range of VRE topics, including transmission and VRE resource data, VRE capacity value, dispatch and operational modeling, distributed generation, and temporal and spatial resolution. The objectives of the workshops were both to better understand these topics and to improve the representation of VRE across the suite of models. Given these goals, each team incorporated model updates and performed additional analyses between the first and second workshops. This report summarizes the analyses and model "experiments" that were conducted as part of these workshops as well as the various methods for treating VRE among the four modeling teams. The report also reviews the findings and learnings from the two workshops. We emphasize the areas where there is still need for additional research and development on analysis tools to incorporate VRE into long-term planning and decision-making.

Note: This research is intended to inform the energy modeling community on the modeling of variable renewable resources, and is not intended to advocate for or against any particular energy technologies, resources, or policies. Scenarios evaluated as part of this work were selected to exercise specific model capabilities, and do not reflect policy preferences or market expectations of the participating organizations or modelers. 


\section{Table of Contents}

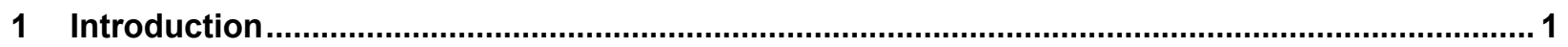

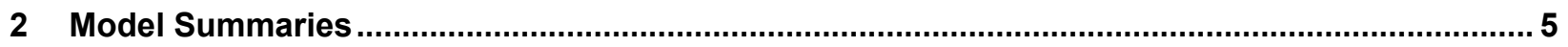

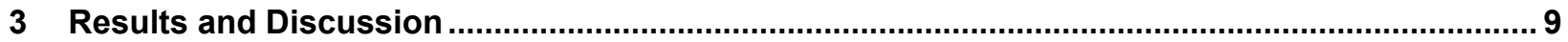

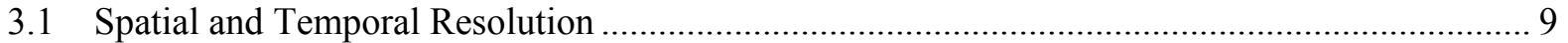

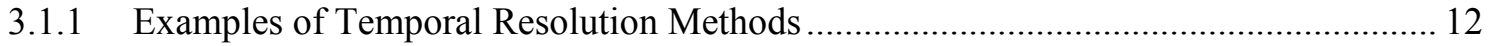

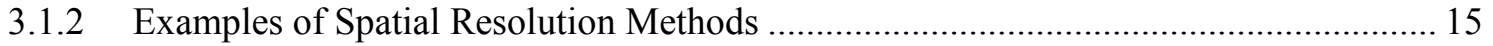

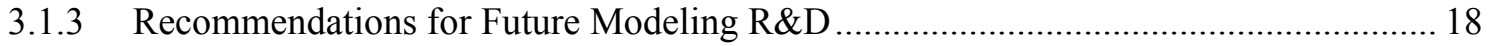

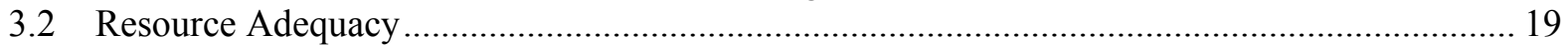

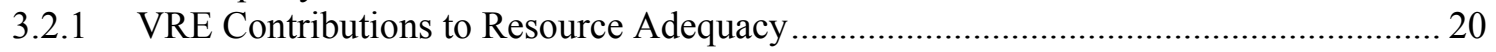

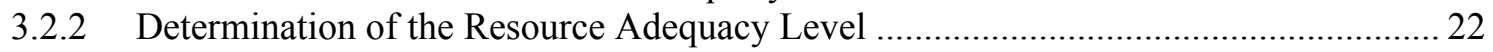

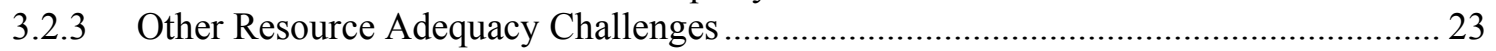

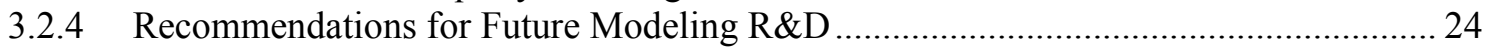

3.3 Economics of Energy Production.............................................................................................. 24

3.3.1 Recommendations for Future Modeling R\&D ...................................................... 28

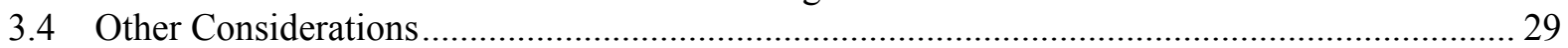

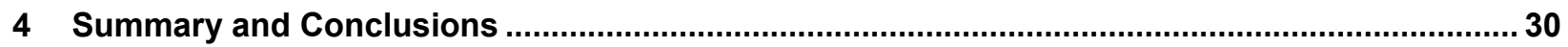

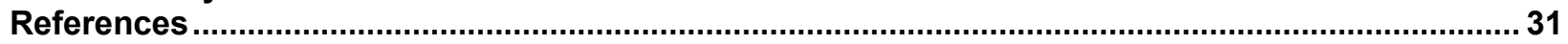

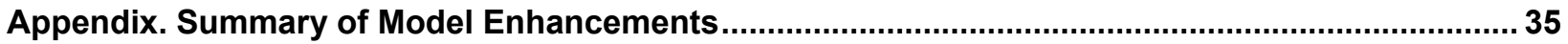

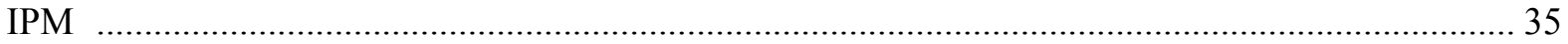

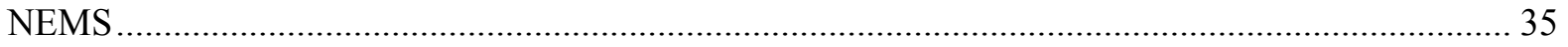

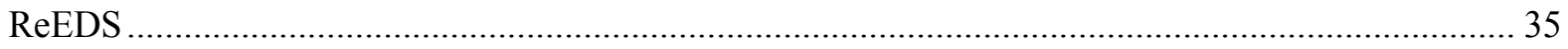

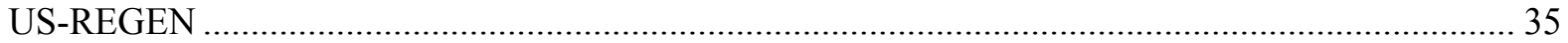




\section{List of Figures}

Figure 1. Native spatial resolution of the four models: 64 IPM regions (top left), 22 NEMS regions (top right), 134 ReEDS balancing area regions (bottom left), and 48 US-REGEN states (bottom right)....

Figure 2. NEMS deployment results with ("w/ Curt") and without ("No Curt") 864 Curtailment

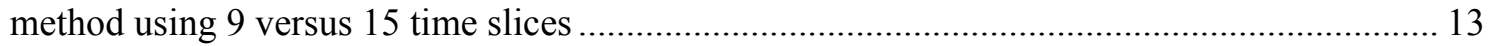

Figure 3. ReEDS LDC-based approach to calculating CV ........................................................ 14

Figure 4. Incremental PV CV using the former and new ReEDS CV method in the Austin, Texas, region (left) and Southern California region (right) ........................................................... 15

Figure 5. Annual production cost savings from 22 aggregated transmission regions (versus 64 native regions) for sample year 2040 ....

Figure 6. Incremental compliance cost of a 50\% wind and solar RPS (relative to a reference scenario without these mandates) with 15 versus 48 US-REGEN regions (Bistline et al. 2017)............. 17

Figure 7. Reserve margins for each NERC assessment area (NERC 2017) .................................... 20

Figure 8. Capacity value for wind (left) and PV (right) as a function of PV and wind penetration..... 22

Figure 9. Coal capacity (left) and nuclear capacity (right) in the model's reference case scenarios.... 23

Figure 10. NEMS generation mix in the reference case when curtailment is included (left) and the difference in generation when curtailment is not included (right) .........................................26

Figure 11. Impact of financing assumptions on the LCOE of a wind plant ...................................... 27

\section{List of Tables}

Table 1. Summary of VRE Attributes Relevant to Capacity Expansion Models .................................. 2

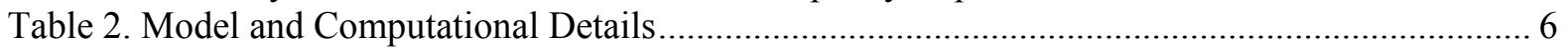

Table 3. Power Sector Constraints/Implementation ....................................................................... 7

Table 4. VRE-Specific Characteristics ..................................................................................... 8

Table 5. Summary of Temporal Resolution and Methods for the Four Models................................ 11

Table 6. ReEDS' Total System Cost with 134 (REF), 48 (STATE), and 13 (NERC) Regions for VRE Representation (Krishnan and Cole 2016)............................................................. 18

Table 7. Summary of How Conventional and VRE Capacity Contribute to Resource Adequacy for the Four Models 21

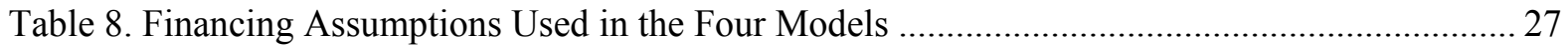

Table 9. Summary of Transmission Connection Costs for VRE Technologies ................................ 28 


\section{Introduction}

Capacity expansion models (CEMs) have long been used as tools by electric utility planners, policymakers, and stakeholders to inform decisions related to the evolution of the power sector. These models typically evaluate the least-cost portfolio of electricity generators, transmission, and storage needed to reliably serve load over many years or decades. By evaluating different possible future scenarios, CEMs can help identify key drivers of change and assess the implications of different generation portfolios.

CEMs vary widely in their geographic scopes, which inform tradeoffs with temporal and spatial resolution modeling choices. For example, CEMs are used to evaluate systems ranging from local systems with tens of megawatts (MW) to national systems with greater than 1,000 gigawatts $(\mathrm{GW})$, such as the four models included in this report. International versions have been used in the integrated assessment model community to evaluate optimal pathways for decarbonizing the global electricity system (e.g., Pietzcker et al. 2014; Pietzcker et al. 2017; IPCC 2015; Edelenbosch et al. 2017). In this report, we take a relatively narrow focus and consider only national-scale models of the U.S. power sector, ${ }^{1}$ as this scope is commonly used to inform national-level decisions for various government and private sector entities. These national-scale models are not as large as integrated assessment models, which generally require more simplified temporal and spatial treatment to accommodate greater model complexity when they include all energy sectors and carriers, all world regions, and the full $21^{\text {st }}$ century. On the other hand, there are regional models with higher resolution but a much narrower scope (e.g., WECC 2013; ABB 2016; Mai et al. 2015; Nelson et al. 2012). These models are typically used for different applications ${ }^{2}$ than the four models in this project and thus are not fully comparable. We do not assess these other classes of models in this work.

Variable renewable energy (VRE) is one of the major sources of complexity in national-scale CEMs because of its physical attributes, which differ from conventional generator technologies, and the need to more accurately represent those attributes. VRE technologies rely on a renewable fuel source and are typically non-dispatchable; in the case of this report, we limit VRE technologies to those that depend on solar and wind generation. ${ }^{3}$ With the rapid increase in VRE deployment over the past decade, the need to accurately represent VRE in CEMs has grown in importance. However, VRE technologies have many differences from conventional technologies, such as natural gas, coal, and nuclear units, which make them more challenging to incorporate into CEMs. Table 2 summarizes many of these VRE attributes, which we compiled from various sources, including Milligan et al. (2016) and Kroposki et al. (2017). These attributes, to varying degrees, have economic implications for VRE, other electric sector investments, and system operations (Ueckerdt et al. 2013; Blanford et al. 2016). For example, VRE plant output is weather-driven and varies considerably from one location to another, while conventional

\footnotetext{
${ }^{1}$ Some national-scale U.S. models also represent portions of the Canadian power system because of the synchronous interconnection ties across the two power systems. Mexican power plants that are part of the Western Electricity Coordinating Council might also be included.

${ }^{2}$ For example, higher-resolution regional models are often used to evaluate individual projects, such as a new plant addition, a new transmission line, or the retirement of a plant.

${ }^{3}$ Although other renewable technologies have variable output, such as conventional hydroelectric or geothermal, their operational conditions are such that they are not considered variable as defined in this report.
} 
Table 1. Summary of VRE Attributes Relevant to Capacity Expansion Models

\begin{tabular}{|c|c|c|}
\hline VRE Attribute & Physical Impact & Relevance for CEMs \\
\hline Variable & $\begin{array}{l}\text { VRE increases the variability of net load (load } \\
\text { minus VRE generation) because its available } \\
\text { power changes through time and space based } \\
\text { on changing weather patterns (e.g., wind } \\
\text { speed or solar irradiance) }\end{array}$ & $\begin{array}{l}\text { Need for appropriate temporal } \\
\text { and spatial resolution to capture } \\
\text { variability and correlations with } \\
\text { other time-series variables } \\
\text { (e.g., load) }\end{array}$ \\
\hline Uncertain & $\begin{array}{l}\text { VRE increases the uncertainty of net load } \\
\text { because the available power cannot be } \\
\text { perfectly forecast at all time horizons. }{ }^{a}\end{array}$ & $\begin{array}{l}\text { Requires methods to account for } \\
\text { adequate operating reserves }\end{array}$ \\
\hline $\begin{array}{l}\text { Near-zero } \\
\text { marginal cost }\end{array}$ & $\begin{array}{l}\text { VRE resources have near-zero or zero variable } \\
\text { production costs because of negligible } \\
\text { operations, maintenance, and fuel costs } \\
\text { (relative to conventional technologies), and } \\
\text { when production-based subsidies exist, this } \\
\text { variable cost can be negative. }\end{array}$ & $\begin{array}{l}\text { Requires proper accounting of high } \\
\text { fixed costs, zero variable cost, and } \\
\text { any relevant production- or } \\
\text { capacity-based subsidies; } \\
\text { potentially requires representation } \\
\text { of market operation impacts and } \\
\text { behavior }\end{array}$ \\
\hline $\begin{array}{l}\text { Lower capacity } \\
\text { value }\end{array}$ & $\begin{array}{l}\text { As a consequence of VRE's variability, VRE } \\
\text { resources have lower capacity value than most } \\
\text { conventional resources because of VRE's } \\
\text { diurnal and seasonal patterns that may result } \\
\text { in low alignments of VRE generation with load } \\
\text { during times of highest system risk to reliability; } \\
\text { when resources are coincident with peak } \\
\text { demand, this contribution from VRE declines } \\
\text { with greater levels of VRE generation. }\end{array}$ & $\begin{array}{l}\text { Requires appropriate methods to } \\
\text { account for VRE's contribution } \\
\text { to resource adequacy needs using } \\
\text { time-synchronized load and VRE } \\
\text { data, and ideally is based on } \\
\text { probabilistic reliability approaches } \\
\text { for identifying highest risk periods } \\
\text { to reliability }\end{array}$ \\
\hline Curtailment & $\begin{array}{l}\text { As a consequence of VRE's variability, VRE } \\
\text { resources can experience times of curtailment } \\
\text { when the remainder of the generator fleet is } \\
\text { unable (for economic, reliability, or other } \\
\text { reasons) to further reduce its operating level to } \\
\text { accommodate VRE generation. }\end{array}$ & $\begin{array}{l}\text { Consideration of VRE curtailment } \\
\text { using temporally-resolved, time- } \\
\text { synchronized load and VRE data } \\
\text { and key thermal generator operating } \\
\text { parameters such as minimum } \\
\text { generation level, ramping } \\
\text { constraints, and shut-down/start-up } \\
\text { costs }\end{array}$ \\
\hline $\begin{array}{l}\text { Geographically } \\
\text { dispersed }\end{array}$ & $\begin{array}{l}\text { The dispersed nature of VRE resources } \\
\text { requires adequate transmission infrastructure } \\
\text { to transport electricity to end users. }\end{array}$ & $\begin{array}{l}\text { Appropriate representation of } \\
\text { transmission network, potentially } \\
\text { including line flows and new } \\
\text { capacity enhancements, as well as } \\
\text { additional costs for "spur lines" } \\
\text { connecting dispersed VRE sites to } \\
\text { existing network infrastructure }\end{array}$ \\
\hline Inverter-based & $\begin{array}{l}\text { VRE technologies are connected to the grid } \\
\text { through power electronic-based inverters, in } \\
\text { contrast to mechanically driven generators with } \\
\text { rotating mass that is synchronized to the grid; } \\
\text { inverters must be carefully designed to supply } \\
\text { necessary grid stability services. }\end{array}$ & $\begin{array}{l}\text { Currently unknown, but might limit } \\
\text { "instantaneous" penetration of VRE } \\
\text { generators because of inertia } \\
\text { limitations }\end{array}$ \\
\hline
\end{tabular}

${ }^{a}$ This uncertainty also impacts the capacity value and curtailment. 
generators are dispatchable and have little variation in their performance across regions. Because of their spatial and temporal diversity, VRE technologies typically require significant amounts of data to be included in CEMs. These traits impose challenges to valuing VRE generation in capacity expansion and dispatch models. Additionally, VRE technologies have evolved rapidly in recent years, so their future costs are difficult to accurately predict (NREL 2017).

These challenges associated with representing VRE in CEMs motivated us to develop a collaboration of four separate modeling teams to assess current best practices, share methods and data, and identify future research needs ${ }^{4}$ using the following four national-scale CEMs:

- Integrated Planning Model (IPM) - U.S. Environmental Protection Agency (EPA)

- National Energy Modeling System (NEMS) - U.S. Energy Information Administration (EIA)

- Regional Energy Deployment System (ReEDS) - National Renewable Energy Laboratory (NREL)

- United States Regional Economy, Greenhouse Gas, and Energy (US-REGEN)—The Electric Power Research Institute (EPRI)

This collaborative research project included two closely-related workshops that examined VRE data and methodologies used by the four national-scale long-term planning models. The workshops were held in December 2016 in Washington, D.C. and in June 2017 in Golden, Colorado. Each of the workshops was one and a half days and covered a wide range of VRE topics, including transmission and VRE resource data, VRE capacity value, dispatch and operational modeling, distributed generation, and temporal and spatial resolution. The objectives of the workshops were both to better understand these topics and to improve the representation of VRE across the suite of models. And, each team incorporated model updates and performed additional analyses between the first and second workshops. A summary of the additional analyses and model "experiments" is provided in the appendix.

This report summarizes the findings and shares what we learned from the two workshops. In particular, we emphasize the areas where there is still need for additional research and development (R\&D) on analysis tools to incorporate VRE into long-term planning and decisionmaking. We note that other collaborative model improvement and comparison efforts have been conducted in the integrated assessment modeling community, such as the Advanced Model Development and Validation for the Improved Analysis of Costs and Impacts of Mitigation Policies (ADVANCE) ${ }^{5}$ project and the Energy Modeling Forum (EMF). ${ }^{6}$ This report and an accompanying paper (Mai et al. forthcoming) ${ }^{7}$ both provide an overview of model improvements and comparisons but applied to CEMs for the U.S. power sector.

\footnotetext{
${ }^{4}$ Modeling teams from this collaboration also conducted a multi-model scenario analysis (Mai et al. forthcoming)

${ }^{5}$ See a description of the ADVANCE initiative and a full set of publications at http://www.fp7-advance.eu/

${ }^{6}$ See a description of the EMF initiative and a full set of publications at https://emf.stanford.edu/

${ }^{7}$ Mai, Bistline, Sun et al. (forthcoming) presents a model scenario exploration, while this report focuses more on methods and key factors for VRE representation.
} 
This report is organized as follows. Section 2 provides a high-level summary of the four models that were included in the workshops. Section 3 presents four themed summaries from the workshop: spatial and temporal resolution, resource adequacy, economics of energy production, and an "other" summary that includes ancillary findings from the workshops. These themed summaries include model method improvements, sensitivity analyses, or both. Each summary ends with a list of key R\&D areas that apply to the theme. Finally, Section 4 presents the conclusions from this work. 


\section{Model Summaries}

Four CEMs were included in this comparison effort: IPM (EPA 2013, 2015b), NEMS (EIA 2017b), ReEDS (Eurek et al. 2016), and US-REGEN (EPRI 2017). These CEMs were developed for different use cases. Because model development is largely guided by the intended use of the model, the differences between the four CEMs is in part driven by their differences in end-use application. As a summary of models and uses:

- EPA's version of IPM is often used to evaluate various emission and environmental policies, such as the Cross-State Air Pollution Rule (CSAPR) and the Mercury and Air Toxics Standards (MATS). ${ }^{8}$ As a result, EPA has focused considerable effort on the representation of fossil-based generator technologies and associated emissions and environmental impacts.

- ReEDS was developed primarily to analyze scenarios with high VRE penetration levels, and it thus has a highly resolved VRE representation.

- NEMS is the EIA's primary tool to provide projections for its Annual Energy Outlook (AEO) reports, which provide a baseline examination of U.S. energy markets and facilitate better understanding of future policies and market evolutions. NEMS has a full linkage of the energy and economy sectors to allow it to more appropriately capture economic feedback and foresight impacts into the energy sector evolution.

- US-REGEN is the newest of the four capacity expansion models. It was built to answer and serve a diverse set of questions, interests, and stakeholders. It was designed to be flexible, including customizable regions and time slices, an adjustable planning horizon, and the capability to link its electric-only model with an economy-wide model, a unit commitment model, and/or an end-use demand model.

Various characteristics of each of the four models covered in the multi-model workshops are summarized in Table 2, Table 3, and Table 4, including some of the differences highlighted above. Of particular focus in these tables are features relevant to the representation of VRE, which was the focus of the workshops. The base version of each model is formulated as a linear program (LP) to facilitate computational tractability. ${ }^{9}$ Additionally, the four models assume a central-planning framework that seeks to minimize the net present value (NPV) of the entire system. ${ }^{10}$ As a result, the models neither represent multiple decision makers nor capture explicit choices of large actors (e.g., corporate power purchase agreements).

\footnotetext{
${ }^{8}$ The IPM model version and projections presented in this report were developed by EPA's Clean Air Markets Division with technical support from ICF International, Inc. The IPM modeling platform is a product of ICF Resources, LLC, an operating company of ICF International and is used in support of its public and private sector clients.

${ }^{9}$ LPs are used for optimal decision making in various industries and applications; as compared to the more complex integer or non-linear mathematical programs, LPs can be solved far more quickly and directly with a guaranteed single optimal solution. We note that, under certain scenario configurations, the US-REGEN model is run as a quadratically constrained program or QCP.

${ }^{10}$ Rooftop PV adoption is an exception - it is modeled using other methods that do not rely on minimizing systemwide NPV.
} 
Table 2. Model and Computational Details

\begin{tabular}{|c|c|c|c|c|c|}
\hline Model & Institution & Objective & $\begin{array}{l}\text { Computational } \\
\text { Requirements }\end{array}$ & Planning Horizon & Foresight \\
\hline IPM & $\begin{array}{l}\text { U.S. Environmental } \\
\text { Protection Agency } \\
\text { (EPA) and ICF }\end{array}$ & $\begin{array}{l}\text { Minimize the NPV of the } \\
\text { power sector's total } \\
\text { annual production costs }\end{array}$ & $\begin{array}{l}\text { 10 hour run time on } \\
\text { computational server }\end{array}$ & $\begin{array}{l}\text { Non-chronological, all } \\
\text { periods solved } \\
\text { simultaneously }\end{array}$ & Perfect foresight \\
\hline NEMS & $\begin{array}{l}\text { U.S. Energy Information } \\
\text { Administration (EIA) }\end{array}$ & $\begin{array}{l}\text { Least cost optimization } \\
\text { for the U.S. electric } \\
\text { power sector; the EMM } \\
\text { projects capacity } \\
\text { planning, generation, } \\
\text { fuel use, transmission, } \\
\text { and pricing of electricity, } \\
\text { subject to inputs and } \\
\text { interactions with other } \\
\text { modules in NEMS. }\end{array}$ & $\begin{array}{l}\sim 8-12 \text { hour run time as } \\
\text { part of integrated } \\
\text { NEMS runs, } \sim 4 \mathrm{~GB} \\
\text { memory }\end{array}$ & $\begin{array}{l}\text { NEMS solves annually } \\
\text { through } 2050 \text {. In EMM } \\
\text { each solve-year } \\
\text { optimizes over a three- } \\
\text { period planning horizon } \\
\text { to examine costs over a } \\
30 \text {-year period, which } \\
\text { consists of the current } \\
\text { year, the next year, and } \\
\text { the final } 28 \text { years of the } \\
\text { cost recovery period. }\end{array}$ & $\begin{array}{l}\text { The model uses } \\
\text { convergent perfect } \\
\text { foresight within the } \\
2050 \text { planning horizon } \\
\text { by using prior run } \\
\text { results as input to the } \\
\text { current run. Out-of- } \\
\text { horizon years use } \\
\text { adaptive foresight. }\end{array}$ \\
\hline ReEDS & $\begin{array}{l}\text { National Renewable } \\
\text { Energy Laboratory } \\
\text { (NREL) }\end{array}$ & $\begin{array}{l}\text { Minimize total system } \\
\text { cost using the } 20 \text {-year } \\
\text { NPV }\end{array}$ & $\begin{array}{l}\sim 8 \text { hour run time, } \sim 12 \\
\text { GB memory }\end{array}$ & $\begin{array}{l}\text { 2-year increments } \\
\text { through } 2050\end{array}$ & $\begin{array}{l}\text { Foresight only for } \\
\text { natural gas and } \mathrm{CO}_{2} \\
\text { prices }\end{array}$ \\
\hline US-REGEN & $\begin{array}{l}\text { Electric Power } \\
\text { Research Institute } \\
\text { (EPRI) }\end{array}$ & $\begin{array}{l}\text { Maximize NPV of } \\
\text { surplus over the model } \\
\text { time horizon } \\
\text { (accounting for end } \\
\text { effects); minimize NPV } \\
\text { if electric sector only } \\
\text { model }\end{array}$ & $\begin{array}{l}\text { Depends on spatial and } \\
\text { temporal resolution: } \sim 1 \\
\text { hour run time, } \sim 32 \mathrm{~GB} \\
\text { memory for } 48 \text {-state } \\
\text { runs }\end{array}$ & $\begin{array}{l}\text { Customizable; for most } \\
\text { analyses, three-year } \\
\text { increments through } \\
2030 \text { and five-year } \\
\text { increments through } \\
2050\end{array}$ & $\begin{array}{l}\text { Intertemporal perfect } \\
\text { foresight }\end{array}$ \\
\hline
\end{tabular}


Table 3. Power Sector Constraints/Implementation

\begin{tabular}{|c|c|c|c|c|}
\hline Model & Temporal Resolution $^{a}$ & Spatial Resolution $^{a}$ & Transmission Representation & Plant Retirements \\
\hline IPM & $\begin{array}{l}12 \text { time slices for each run } \\
\text { year ( } 2 \text { seasons x } 6 \\
\text { segments) through } 2030 ; 8 \\
\text { time slices ( } 2 \text { seasons } \times 4 \\
\text { segments) for all post- } 2030 \\
\text { run years }\end{array}$ & $\begin{array}{l}64 \text { regions covering the } \\
\text { contiguous United States } \\
\text { ( } 61 \text { power market regions } \\
\text { and } 3 \text { power switching } \\
\text { regions), with } 11 \text { additional } \\
\text { provincial power market } \\
\text { regions representing } \\
\text { southern Canada }\end{array}$ & $\begin{array}{l}\text { Firm and non-firm total transfer } \\
\text { capabilities between regions; joint } \\
\text { transmission capacity and energy } \\
\text { limits; wheeling charges between } \\
\text { regional transmission } \\
\text { organizations; static interregional } \\
\text { transmission losses }\end{array}$ & $\begin{array}{l}\text { Economic retirements for all } \\
\text { non-VRE technologies; VRE } \\
\text { technologies assumed to } \\
\text { incur life extension costs to } \\
\text { continue operation indefinitely }\end{array}$ \\
\hline NEMS & $\begin{array}{l}\text { Hourly loads are divided into } \\
3 \text { seasonal periods (summer, } \\
\text { winter, and spring/fall). For } \\
\text { each season, the loads are } \\
\text { divided into } 3 \text { groups: peak } \\
\text { (highest } 1 \% \text { ), intermediate } \\
\text { (next } 49 \% \text { ), and base (lowest } \\
50 \% \text { ), totaling } 9 \text { segments. }\end{array}$ & $\begin{array}{l}\text { The generation of } \\
\text { electricity is accounted for } \\
\text { in } 22 \text { supply regions that } \\
\text { resemble the North } \\
\text { American Electric } \\
\text { Reliability Corporation } \\
\text { (NERC) reliability } \\
\text { assessment regions. }\end{array}$ & $\begin{array}{l}\text { NERC collects data and } 10 \text {-year } \\
\text { projections of demand, generating } \\
\text { and transmission capacity, and } \\
\text { capacity purchases and sales, by } \\
\text { region and/or by utility. These data } \\
\text { are used as input to capture firm } \\
\text { power transactions. }\end{array}$ & $\begin{array}{l}\text { Announced retirements are a } \\
\text { model input. The model also } \\
\text { evaluates retirement } \\
\text { decisions for fossil and } \\
\text { nuclear based on whether } \\
\text { continuing operation costs } \\
\text { exceed revenues and if new } \\
\text { capacity is more economical. }\end{array}$ \\
\hline ReEDS & $\begin{array}{l}17 \text { Time slices ( } 4 \text { per day x } 4 \\
\text { seasons + summer afternoon } \\
\text { super-peak) across one year }\end{array}$ & $\begin{array}{l}\text { Contiguous United States } \\
\text { with } 134 \text { load balancing } \\
\text { areas and } 18 \text { resource } \\
\text { adequacy regions; some } \\
\text { representation of Canada } \\
\text { and Mexico }\end{array}$ & $\begin{array}{l}\text { Approximate DC power flow } \\
\text { between } 134 \text { load regions; } \\
\text { susceptances and line capacities } \\
\text { updated between each solve } \\
\text { period; VRE spur lines represented } \\
\text { within regions }\end{array}$ & $\begin{array}{l}\text { Age-based retirements for all } \\
\text { technologies; additionally, } \\
\text { minimum capacity factor- } \\
\text { based retirements for coal }\end{array}$ \\
\hline US-REGEN & $\begin{array}{l}\text { Customizable; typically 100+ } \\
\text { "representative hours" } \\
\text { (Blanford et al. 2016) per year }\end{array}$ & $\begin{array}{l}\text { Contiguous United States; } \\
\text { customizable regions } \\
\text { based on state boundaries }\end{array}$ & $\begin{array}{l}\text { Pipeline representation of flows } \\
\text { across existing and new interstate } \\
\text { transmission lines; carrying } \\
\text { charges and line losses included; } \\
\$ 450 \text { per kilowatt }(\mathrm{kW}) \\
\text { transmission adder for new } \\
\text { renewables }\end{array}$ & $\begin{array}{l}\text { Exogenous retirements for } \\
\text { most technologies due to } \\
\text { announced closures and age- } \\
\text { based retirements; } \\
\text { endogenous economic } \\
\text { retirements also possible }\end{array}$ \\
\hline
\end{tabular}

\footnotetext{
${ }^{a}$ As applied to the dispatch process within the models
} 
Table 4. VRE-Specific Characteristics

\begin{tabular}{|c|c|c|c|}
\hline Model & VRE Spatial Resolution & $\begin{array}{l}\text { Out of Optimization } \\
\text { VRE Treatment }\end{array}$ & Distributed PV \\
\hline IPM & $\begin{array}{l}\text { Onshore wind resource is allocated to five potential } \\
\text { resource classes across three potential cost } \\
\text { classes for each of the } 110 \text { state and IPM region } \\
\text { combinations in the contiguous United States. } \\
\text { Solar photovoltaic (PV) resource is divided among } \\
122 \text { state and IPM region combinations. }\end{array}$ & None & $\begin{array}{l}\text { PV deployment reflected in net } \\
\text { energy for load taken from EIA's } \\
\text { AEO. No distributed PV build } \\
\text { options are modeled in IPM. }\end{array}$ \\
\hline NEMS & $\begin{array}{l}\text { Solar: } 22 \text { regions } \\
\text { Wind: } 22 \text { regions and } 4 \text { resource classes }\end{array}$ & $\begin{array}{l}\text { Between each solve period, a } \\
\text { statistical algorithm estimates } \\
\text { marginal curtailment rates using a } \\
\text { sequential } 864 \text { hourly model. }\end{array}$ & $\begin{array}{l}\text { Small-scale solar PV is } \\
\text { endogenously modeled in the end- } \\
\text { use module of NEMS through a } \\
\text { hurdle model approach using Zip } \\
\text { code-level data. }\end{array}$ \\
\hline ReEDS & $\begin{array}{l}\text { PV: } 134 \text { regions and } 9 \text { resource classes } \\
\text { Concentrating solar power (CSP): } 356 \text { regions and } \\
5 \text { resource classes } \\
\text { Land-based wind: } 356 \text { regions and } 10 \\
\text { resource classes } \\
\text { Offshore wind: } 70 \text { regions and } 15 \text { resource classes }\end{array}$ & $\begin{array}{l}\text { Between each solve period, the } \\
\text { model calculates capacity value with } \\
\text { hourly data and estimates } \\
\text { curtailment and forecasting error } \\
\text { reserve requirement with a statistical } \\
\text { method. }\end{array}$ & $\begin{array}{l}\text { Exogenous rooftop PV adoption } \\
\text { from dGen model }^{\mathrm{a}}\end{array}$ \\
\hline US-REGEN & $\begin{array}{l}\text { PV: } 5 \text { resource classes for each model region; } 3 \\
\text { solar technology options for each class (fixed tilt, } \\
\text { single-axis tracking, or double-axis tracking) } \\
\text { CSP: } 5 \text { resource classes for each model region } \\
\text { Onshore wind: } 8 \text { resource classes for each model } \\
\text { region } \\
\text { Offshore wind: } 1 \text { resource class for each } \\
\text { model region }\end{array}$ & None & $\begin{array}{l}\text { Distributed generation (including } \\
\text { rooftop PV) retail market model } \\
\text { iterates with the electric sector } \\
\text { model }\end{array}$ \\
\hline
\end{tabular}

\footnotetext{
${ }^{a}$ See https://www.nrel.gov/analysis/dgen/.
} 


\section{Results and Discussion}

\subsection{Spatial and Temporal Resolution}

One of the most apparent differences among — and significant challenges with — the models included in this multi-model effort is model resolution, both in the spatial and temporal dimensions. Because the level of spatial and temporal resolution used in these models is a key factor in the representation of variability and correlation of load and VRE resources, the resolution can have a substantial impact on both the VRE and overall model solutions. Too little resolution can fail to capture important correlations or the full distribution of high- and lowquality VRE resources and other time-series variables (see Table 1), while too much resolution can cause the model to become computationally intractable or have data requirements that are currently unrealistic. The "right" choice of resolution often depends on the research question being addressed. And, because that choice is typically unknown, we explore in this section the spatial and temporal resolution of the models and the effects of changing that resolution.

Spatial resolution is reflected by the number of subnational geographical regions, each of which is typically associated with its aggregate load, VRE resource availability, and conventional generator fleet. Depending on the model, these regions may be defined by state boundaries, cross-state or sub-state balancing areas, or other planning-relevant zones. The intraregional resolution of VRE resources varies by model and is a function of the granularity of VRE cost, resource quality, and resource availability data. Each region is typically represented as a single node within a transmission network topology. ${ }^{11}$ As shown in Figure 1, the spatial extent of the four models included here each captures, at a minimum, the contiguous United States, but IPM also endogenously represents Canada. ${ }^{12}$ Within this spatial extent, the models have a wide range in the number and size of regions. This resolution sometimes varies by system component or model configuration. For example, in ReEDS, some VRE resources are represented by 356 resource regions, while more spatially homogenous resources are resolved into the native 134 load balancing regions. US-REGEN provides a user-specified spatial resolution, up to the 48 contiguous states. Furthermore, the NEMS and IPM models have developed methodologies to capture sub-regional boundaries that are either explicitly synchronized to the model regions or implicitly embedded within the boundaries of smaller regional definitions, which are used to capture state and regional policies within model constraints.

\footnotetext{
${ }^{11}$ Each region in these models is a node, so $22-134$ nodes are represented in them (see Table 3 ).

12 Other CEMs, including integrated assessment models and computable general equilibrium models, extend beyond just the power sector and can have a much broader scope, covering other economic sectors and geographic regions, such as entire continents or the full globe. As discussed earlier, NEMS includes a full representation of the U.S. energy-economy, but our project is focused primarily on the electricity market module within NEMS.
} 


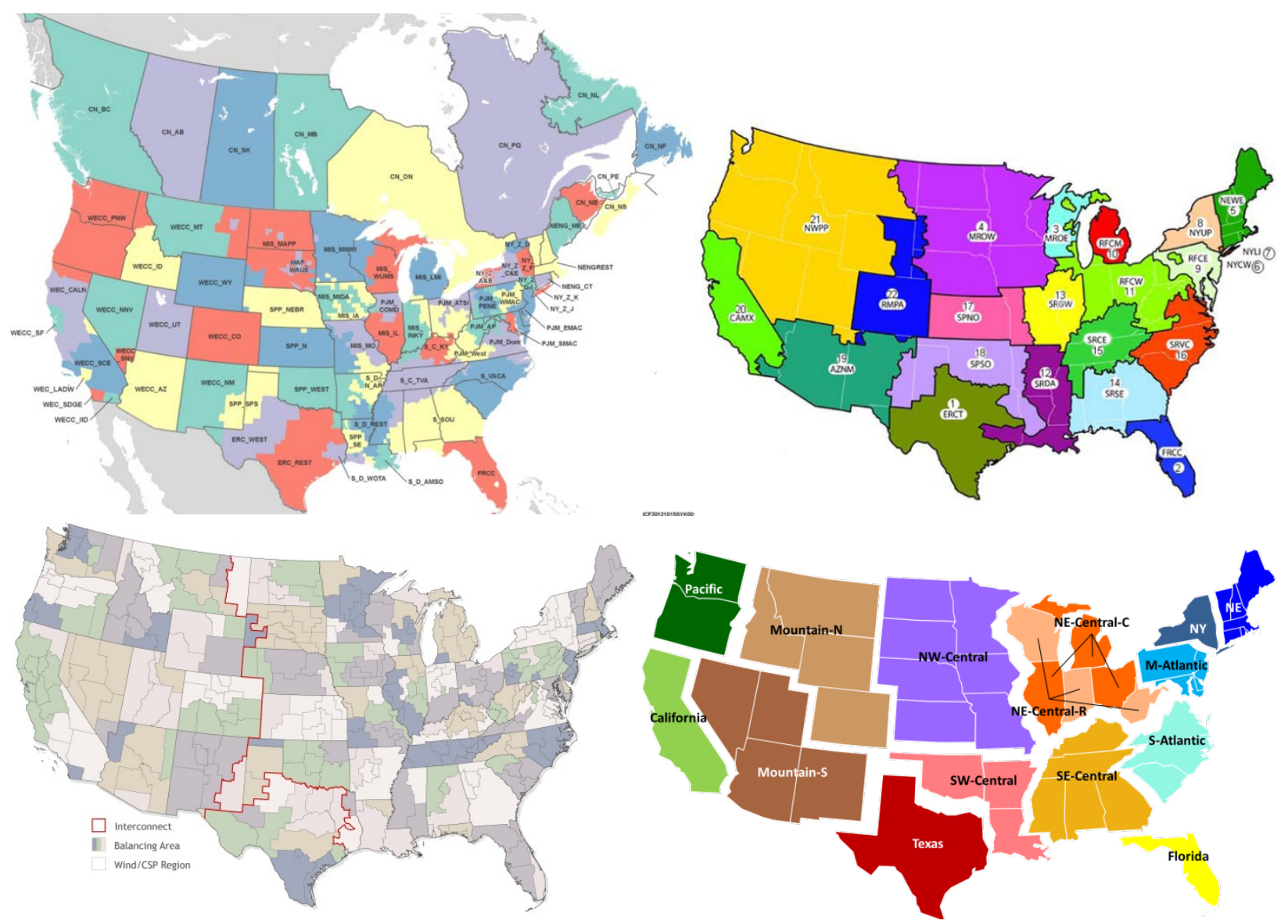

Figure 1. Native spatial resolution of the four models: 64 IPM regions (top left), 22 NEMS regions (top right), 134 ReEDS balancing area regions (bottom left), and 48 US-REGEN states (bottom right)

Because of computational limitations, these four national-scale planning models are unable to represent both the investment decisions and a fully resolved operational dispatch process across a full year. As a result, representative time intervals ("time slices") are typically used to represent a full year of 8,760 hours (or a greater number of sub-hourly time steps). The temporal resolution of the model dispatch refers to the number of such time slices. Numerous methods exist exogenously selecting individual hours or representative time steps from a full year of data; these include clustering techniques to select characteristic, aggregating similar hours, and using characteristic time blocks by day and/or season (Getman et al. 2015; Blanford et al. 2016; Nahmmacher et al. 2016; Santen et al. 2017). Temporal resolution is also reflected in the underlying VRE data used in these down-scaling methods, as well as in metrics calculated outside the optimization (but still endogenous to the model) to capture intra-time-slice VRE characteristics. Aspects of the various temporal resolution and methods used by the four CEMs are summarized in Table 5. One disadvantage of using time slices, which is shared by all these models, is the non-chronological nature of the resulting dispatch steps, which augments challenges associated with modeling energy storage, end-use demand response, and other technologies with strong interdependencies across time slices. Furthermore, by nature of being long-term planning models, the temporal extent of each of these models is decades into the future, typically through 2050 . However, the time steps along the investment time horizon and model foresight can vary (see Table 2). 
Table 5. Summary of Temporal Resolution and Methods for the Four Models

\begin{tabular}{|c|c|c|c|c|}
\hline Model & $\begin{array}{l}\text { Underlying } \\
\text { VRE Data } \\
\text { Resolution }\end{array}$ & $\begin{array}{l}\text { Dispatch } \\
\text { Resolution }\end{array}$ & $\begin{array}{l}\text { Dispatch Resolution } \\
\text { Method }\end{array}$ & $\begin{array}{l}\text { Intra-time-slice VRE } \\
\text { Parameter Resolution }\end{array}$ \\
\hline IPM & $\begin{array}{l}\text { Hourly } \\
\text { (“8760") load } \\
\text { and VRE time } \\
\text { series data }\end{array}$ & $\begin{array}{l}12 \text { time slices } \\
\text { through } 2030 \\
8 \text { thereafter }\end{array}$ & $\begin{array}{l}6 \text { stylized time blocks across } \\
\text { load duration curve for each } \\
\text { of } 2 \text { seasons; } 4 \text { stylized time } \\
\text { blocks for post- } 2030 \text { run } \\
\text { years. }\end{array}$ & NA \\
\hline NEMS & $\begin{array}{l}\text { Hourly (8760) } \\
\text { load and VRE } \\
\text { time series } \\
\text { data }\end{array}$ & 9 time slices & $\begin{array}{l}3 \text { load-based time segments } \\
\text { (peak, shoulder, base) per } \\
\text { each of } 3 \text { seasons (summer, } \\
\text { winter, fall/spring) }\end{array}$ & $\begin{array}{l}\text { Curtailment calculated } \\
\text { from } 864 \text { representative } \\
\text { hours ( } 3 \text { day types } \times 24 \\
\text { hours } \times 12 \text { months) } \\
\text { (see Section } 3.1 .1 \text { ) }\end{array}$ \\
\hline ReEDS & $\begin{array}{l}\text { Hourly ( } 8760) \\
\text { load and VRE } \\
\text { time series } \\
\text { data }\end{array}$ & 17 time slices & $\begin{array}{l}\text { Fixed time blocks: } 4 \text { time } \\
\text { slices per day per each of } \\
\text { the } 4 \text { seasons, plus a super } \\
\text { peak summer afternoon } \\
\text { period }\end{array}$ & $\begin{array}{l}\text { Capacity value } \\
\text { calculated from hourly } \\
(8760) \text { load and VRE } \\
\text { time series data (see } \\
\text { Section } 3.1 .1 \text { ) }\end{array}$ \\
\hline $\begin{array}{l}\text { US- } \\
\text { REGEN }\end{array}$ & $\begin{array}{l}\text { Hourly (8760) } \\
\text { load and VRE } \\
\text { time series } \\
\text { data }\end{array}$ & $\begin{array}{l}\text { User-defined; } \\
\text { typically } \sim 100 \\
\text { time slices }\end{array}$ & $\begin{array}{l}\text { Clustering method to capture } \\
\text { both extreme events and } \\
\text { representative hours } \\
\text { throughout the year }\end{array}$ & NA \\
\hline
\end{tabular}

A key theme that emerged from the multi-model comparison workshops was that the selection method for temporal and spatial resolution can be as important as the resolution itself. These methods include techniques both outside and inside the optimization code. Outside methods focus on capturing the subset of the most important locations or times in order to reduce model complexity. Inside methods aim to improve resolution through dispatch decision variables, for example, by increasing the number of time slices or increasing the number of VRE resource classes. The outside methods include both methodologies that update parameters between solve periods ${ }^{13}$ and methodologies used to select exogenous parameters (e.g., how should time slices be created?). The way in which these outside methods can be pursued range from direct incorporation (e.g., building a methodology into a model) to using a separate, higherresolution model to inform parameter selection.

Much of the current model enhancement work among the teams included in this multi-model exercise focuses on developing sophisticated outside methods. This effort includes representing temporal and/or spatial system interactions that would be too complex and/or computationally burdensome to include within the model while maintaining an LP formulation. For several of the modeling teams, improved temporal methods aim to calculate metrics outside the optimization to approximate intra-time-period variability and/or uncertainty. We detail two examples below, from the NEMS and ReEDS models. Improved spatial methods include the

\footnotetext{
${ }^{13}$ NEMS and ReEDS are sequential models, so parameters can be updated between solve periods. For example, after solving for the year 2020, ReEDS and NEMS employs nonlinear VRE calculations to update VRE parameters that impact the value of VRE (e.g., from curtailment) before proceeding to the next year.
} 
use of higher-resolution exogenous supply or cost curves to approximate intraregional distributions of site-level features for VRE and other resource availability. The resolution can be further improved by subdividing these resources into resource quality classes. In the spatial method examples below with the IPM, US-REGEN, and ReEDS models, we show how the seemingly simple choice of the number of regions can yield very different model results based on the treatment of VRE resources.

\subsubsection{Examples of Temporal Resolution Methods}

The "outside" temporal resolution selection methods detailed here reflect efforts by the NEMS and ReEDS modeling teams to improve the calculation of intra-time slice metrics, specifically to capture the impact on PV curtailment and VRE capacity value respectively. The NEMS example demonstrates the impact of increasing the number of model time slices. As we will see, there are tradeoffs in computation time and model results between the numbers of time slices and how intra-time-slice characteristics are represented. The results presented here suggest that improved methodologies for calculating intra-time-slice characteristics provide a similar temporal resolution benefit to approaches that only increase the number of time slices but they do so with a smaller increase in computational burden.

NEMS represents load, VRE resources, and dispatch across nine time slices: three seasons (summer, winter, and fall/spring) each with three load-based time segments (peak, shoulder, and base). To capture intra-time-slice behavior, EIA implemented a "864 method" to estimate PV curtailment within these time slices based on 864 hours across the year (12 months each with 24 hours and 3 load-based day types that correspond to weekday and weekend variations in demand). Within each of the 864 time slices, the method computes the adjusted energy value of PV after any generation in excess of net demand (after accounting for minimum generation limits of units with limited cycling capability). As solar generation begins to saturate the demand during daylight hours within each month, the apparent value of the resource (as measured by the cost of displaced energy) is reduced. This energy value parameter is then aggregated back to the nine time slices used in the LP, and it is passed to that process as an adjustment to the cost of PV. In addition, this approach has been extended to wind curtailments and energy storage.

While developing the new approach, EIA also investigated increasing the temporal resolution of the LP itself, focusing on adding time slices to provide more resolution around daylight and nighttime hours. While time slices were added as a way to quickly assess the impact of the low temporal resolution on PV model results prior to more-involved model development, the expectation was that the impact on execution time would be too severe to operationalize in the production NEMS model. However, this limited development provides a reasonable benchmark against which the final 864 algorithm can be compared for both model impact and performance. A comparison of with ("w/ Curt") and without ("No Curt") curtailment using the 864 method and 9 versus 15 time slices is shown in Figure 2. Deployment is generally unaffected, except for PV, which sees a reduction in buildout with both the 864 method and 15 time slices, suggesting both methods achieve similar temporal resolution improvements of capturing the curtailment impact at higher PV penetration levels. ${ }^{14}$ However, increasing the number of time slices had a significantly greater impact on run time than the 864 method. In high VRE deployment

\footnotetext{
${ }^{14}$ Because of the wind/PV trade-off, wind deployment is increased as the PV deployment decreases.
} 
scenarios, run times increased by no more than $6 \%$ with the 864 method, while run times increased by over $20 \%$ with 15 time slices. In summary, the 864 curtailment algorithm leads to similar deployment results, represents PV generation with higher granularity, and has minimal impact on run times, compared to increasing number of time slices.

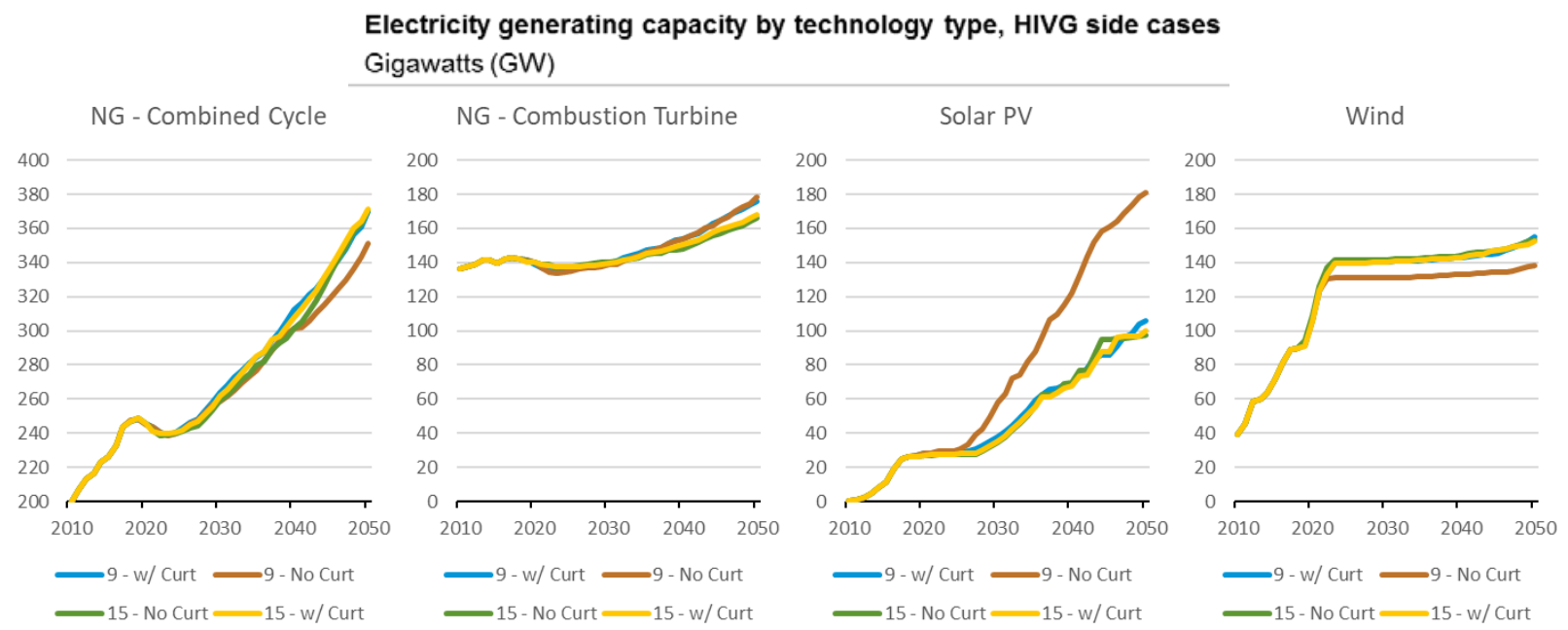

Figure 2. NEMS deployment results with ("w/ Curt") and without (“No Curt”) 864 Curtailment method using 9 versus 15 time slices

HIVG = high variable generation

The second example of "outside" methods to improve temporal resolution is with the ReEDS "8760 method" that is based on time-synchronous hourly load (i.e., 8,760 hours) and VRE data. As shown in Figure 3, this approach approximates the capacity value (CV) of VRE as the difference between the top 100 hours of the load duration curve (LDC) and the net load duration curve (NLDC). This approach further estimates the marginal CV of potential new VRE generators as the difference between the NLDC and incremental NLDC (NLDC $(\delta))$ ). This methodology is detailed by Frew et al. (2017) and was developed in coordination with a similar methodology implemented in NREL's Resource Planning Model or RPM (Hale, Stoll, and Mai 2016). While this LDC-based approach for CV is not itself novel (e.g., IEA 2015), it (1) demonstrates how a simplified 8760 hourly method more accurately captures CV trends than a statistical method within the ReEDS CEM and (2) provides a flexible modeling framework from which other 8760-based system elements (e.g., demand response, storage, and transmission) can be added to further capture important dynamic interactions, such as curtailment. 


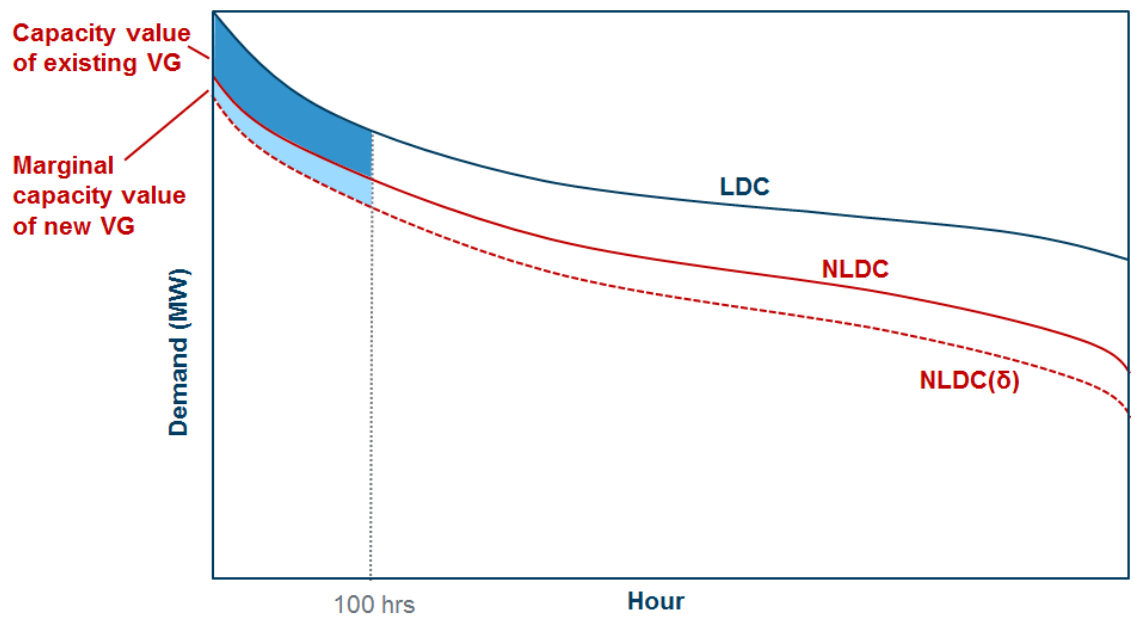

Figure 3. ReEDS LDC-based approach to calculating CV

ReEDS previously estimated CV using a statistical approach that considered simple summary metrics (variance and expected value) from the underlying hourly load and resource data within each of the 17 time slices. ${ }^{15}$ ReEDS optimizes investment decisions within two-year solve periods, sequentially solving from the present day system out to the model horizon of 2050. The CV parameters are updated between each of these two-year solve periods and then used in the subsequent solve period in ReEDS to quantify each VRE resource's capacity contribution to the planning reserve constraint.

Results suggest that the new 8760 method offers a more accurate representation of VRE CV in ReEDS than the former statistical approximation method with less than a $10 \%$ increase in solve time. The marginal PV CV outputs derived by the former ReEDS statistical method and the new 8760 method are shown in Figure 4. The new ReEDS method better captures the declining capacity value of VRE with increasing levels of penetration (see also Section 3.2). Previous work has shown, and Figure 4 supports, that the former ReEDS CV method yields abrupt changes in $\mathrm{CV}$ between the different time slices, particularly between summer afternoon and evening (Sigrin et al. 2014). These results can be seen in Figure 4's left pane by the sharp drop in the former ReEDS method marginal CV around the 7\% PV penetration level, where the planning reserve constraint binding time slice shifts from summer afternoon to evening (yellow diamonds). Furthermore, as the right pane shows, the coarse time-slice-based values in the former ReEDS method often estimate persistently high CVs for PV even at relatively high penetration levels. The new 8760-based method (red triangles), which looks across the top 100 net load hours to calculate an annual $\mathrm{CV}$, results in a smoother and more rapid decline in $\mathrm{CV}$.

\footnotetext{
${ }^{15}$ ReEDS still uses this statistical approach for estimating VRE curtailment and forecast reserve errors. And, as with the CV method, these other statistical approaches happen "outside" the optimization.
} 

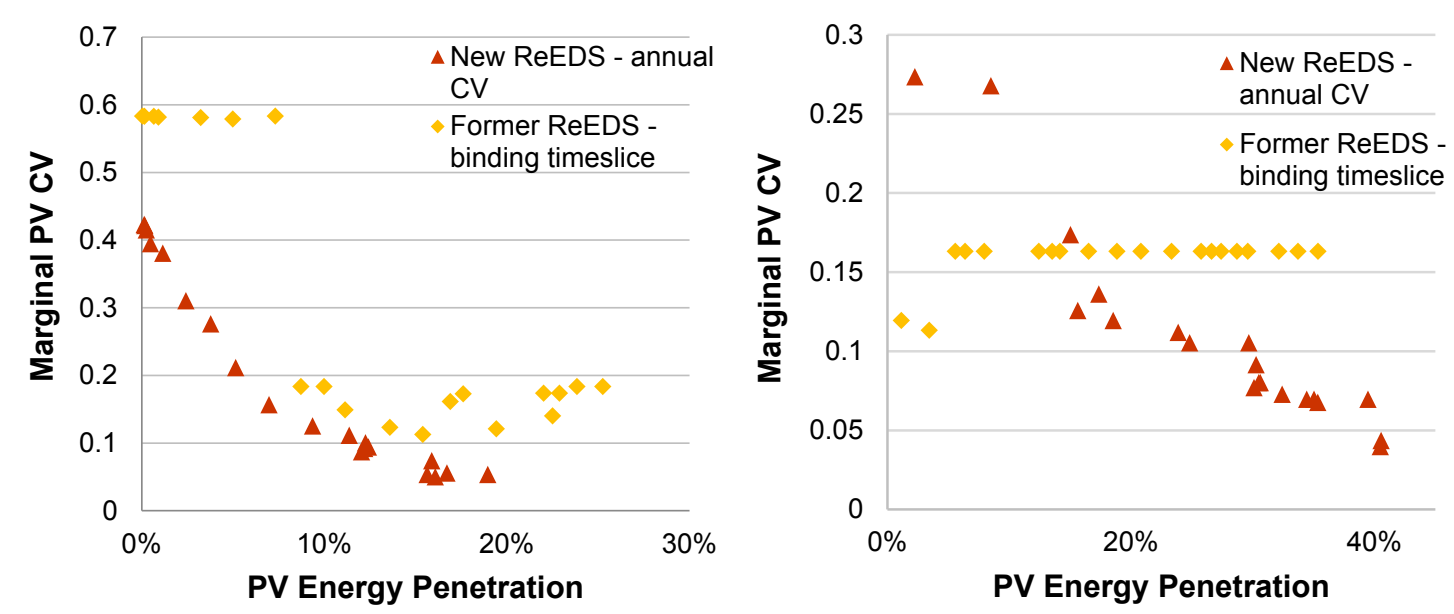

Figure 4. Incremental PV CV using the former and new ReEDS CV method in the Austin, Texas, region (left) and Southern California region (right)

In summary, these examples show how the temporal resolution can significantly impact the value of VRE to the system. Insufficient temporal resolution can lead to overvaluing VRE, especially PV, by underestimating VRE curtailment and overestimating capacity value. However, increased temporal resolution typically requires higher-resolution data and often increases model runtime.

\subsubsection{Examples of Spatial Resolution Methods}

The four models discussed in this report differ significantly in the number of geographic regions they represent. In this section, we show how the method for constructing various spatial resolutions can yield opposing trends in some model results. In particular, as shown with examples from the IPM, US-REGEN, and ReEDS models, the treatment of VRE resources can drive total system costs to either increase or decrease with greater spatial resolution, depending on the method for increasing the resolution.

The IPM model includes 64 U.S. regions. To examine how the spatial resolution of transmission system representation impacts modeling projections, an alternate version of IPM was created by eliminating transmission constraints, charges, and losses between select IPM regions. The aggregated transmission regions were designed to approximate the 22 regions of the EMM in NEMS. ${ }^{16}$ All other regional parameters, such as resource supply curves, were maintained at the 64-region level. To quantify the impact of this change, a minimum generation constraint was imposed in both versions of IPM that required wind and solar resources to supply generation equal to $40 \%$ of load by $2040 .{ }^{17} \mathrm{In}$ the version of IPM with aggregated transmission regions, the model was able to produce the prescribed level of VRE penetration in 2040 at a 5\% savings in total annual production costs ( $\$ 9.5$ billion in $2016 \$$ ), relative to the standard IPM version. These savings were achieved through greater utilization of more remote but higher-resource wind, ${ }^{18}$ which allows for (1) $13 \mathrm{GW}$ in avoided solar capacity, (2) a slight shift away from higher fixedcost coal to more flexible natural gas resources (an incremental $9 \mathrm{GW}$ of coal is retired under the

\footnotetext{
${ }^{16}$ Transmission limits, charges, and losses are maintained between the aggregated regions.

${ }^{17}$ The constraint requires VRE generation equal to or greater than $17.5 \%$ of load by $2025 ; 22 \%$ of load by 2028 ; $25 \%$ of load by $2030 ; 32.5 \%$ of load by $2035 ; 40 \%$ of load by 2040 .

${ }^{18}$ The wind fleet is $1 \mathrm{GW}$ smaller but produces 20 terawatt-hours (TWh) more generation in 2040.
} 
aggregated transmission region version), and (3) a small overall reduction in total capacity and generation through avoided transmission losses. These factors are reflected in the components of production cost savings presented for a sample year in Figure 5, with the primary driver of cost savings in the aggregated transmission region run being the avoided $13 \mathrm{GW}$ of new solar capacity. On an NPV basis, the cost savings from 2016 to 2040 realized by aggregating transmission regions is $\$ 104.4$ billion (2016\$), of which $\$ 73.0$ billion is attributable to avoided capital expenditures. In other words, if IPM lacked the regional resolution in VRE-relevant constraints that was eliminated for this scenario, it might underestimate the system cost and capacity additions needed to reach this level of VRE generation.

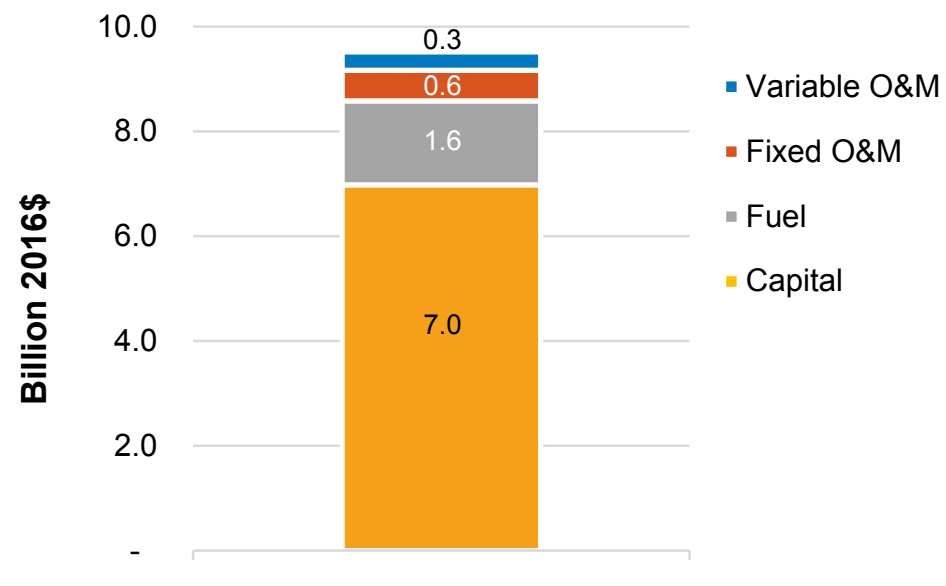

Figure 5. Annual production cost savings from 22 aggregated transmission regions (versus 64 native regions) for sample year 2040

US-REGEN performed a similar comparison of the 48 contiguous states against a smaller set of 15 regions, as detailed in Bistline et al. (2017). The 48-state resolution is currently the finest spatial resolution for planning decisions in US-REGEN. Similarly to the IPM example, the intraregional transmission constraints were collapsed within the 15-region case, but other intraregional parameters were maintained. Like IPM, the US-REGEN model with lower spatial resolution had lower system costs (see Figure 6). Cost differences are amplified by policy constraints such as a 50\% national renewable mandate by 2050 (the "RPS" scenario in Figure 6) as well as market conditions such as gas prices or limitations on trade. Incremental electric sector costs relative to the reference in Figure 6 are shown assuming full interregional renewable energy certificate trade and with restrictions on such trade. With fewer regions, there were fewer transmission constraints, making it easier to access lower-cost VRE resources. Total system costs were approximately $2 \%$ lower in the 15 -region case than in the 48 -region case. 


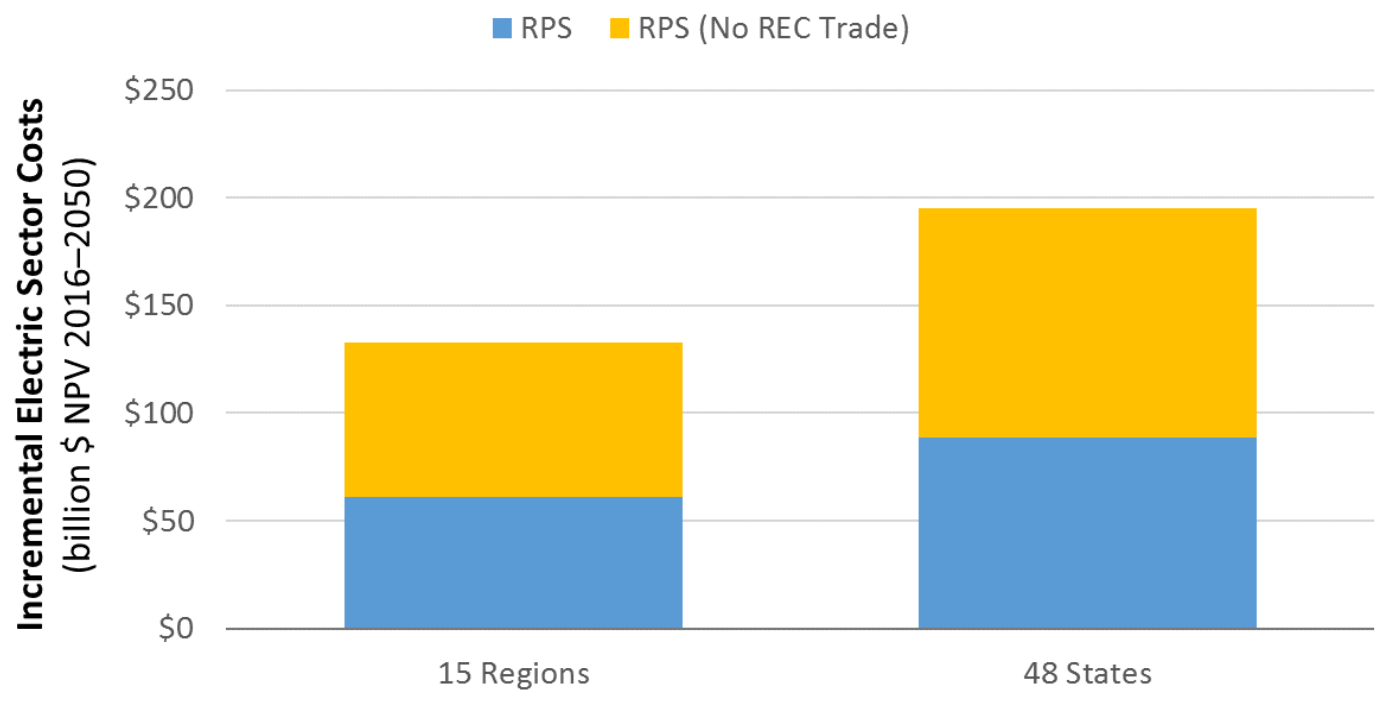

Figure 6. Incremental compliance cost of a $50 \%$ wind and solar RPS (relative to a reference scenario without these mandates) with 15 versus 48 US-REGEN regions (Bistline et al. 2017)

In the ReEDS example, instead of adjusting transmission constraints to match varying levels of regional aggregation, the impact of spatially aggregating VRE resources within a constant transmission topology was evaluated (Krishnan and Cole 2016). Three aggregation scenarios were considered: 134 native regions ("REF"), 48 contiguous U.S. states ("STATE"), and 13 approximate North American Electric Reliability Corporation regions ("NERC"). For each level of aggregation, the VRE cost and performance characteristics were averaged (capacity-weighted) to obtain a single supply curve for each resource within each region evaluated, but other regional parameters, such as the transmission system were left at the native 134-region resolution. ${ }^{19}$ Unlike the trend observed by IPM and US-REGEN, the total system cost increased as the VRE resource was aggregated, as shown in Table 6 . This is driven by the impact of averaging higherand lower-quality VRE resources, yielding smoother supply curves that fail to capture the full distribution of resource quality and resulting competitiveness among sites and across technologies. With a more aggregate resource representation, the model can no longer see the best-quality, lowest-cost sites that were available in the more spatially resolved representation.

\footnotetext{
${ }^{19}$ Within each region, ReEDS includes 10 wind classes (called techno-resource groups), 9 PV classes, and 5 CSP classes. In this example, the classes were maintained but were aggregated with other similar classes in that region.
} 
Table 6. ReEDS' Total System Cost with 134 (REF), 48 (STATE), and 13 (NERC) Regions for VRE Representation (Krishnan and Cole 2016)

\begin{tabular}{lrrr}
\hline Category (2015\$) & \multicolumn{1}{c}{ REF } & STATE & NERC \\
\hline Conventional capital & 345 & 356 & 356 \\
Conventional O\&M & 840 & 844 & 846 \\
Conventional Fuel & 2,160 & 2,190 & 2,235 \\
Renewable capital & 614 & 598 & 570 \\
Renewable O\&M & 239 & 236 & 237 \\
Renewable Fuel & 24 & 24 & 25 \\
Storage capital & 2.5 & 2.2 & 2.1 \\
Storage O\&M & 9.3 & 9.1 & 9.1 \\
All transmission & 61 & 63 & 66 \\
Water & 0.02 & 0.02 & 0.02 \\
\hline Total & $\mathbf{4 , 2 9 8}$ & $\mathbf{4 , 3 2 3}$ & $\mathbf{4 , 3 4 7}$ \\
\hline Difference & & $\mathbf{2 5}$ & $\mathbf{4 9}$ \\
\hline
\end{tabular}

In summary, these examples show that insufficient spatial resolution can lead to either under- or over-representing the cost of building out a system, depending on how the spatial aggregation takes place. Aggregating the transmission leads to lower costs because lower-cost but moreremote resources can contribute to the system with fewer transmission limitations. Aggregating the VRE resources leads to higher costs because the highest-quality resource sites are averaged with mid- or low-quality sites, reducing the model's ability to "see" the lowest-cost VRE potential. Higher spatial resolution, however, necessitates higher-resolution spatial data and, because of the linear nature of these models, can lead to false precision (e.g., a very minor cost difference between two small regions might mean all new capacity is built in the slightly less expensive region). Additionally, increases in spatial resolution can increase model run time.

\subsubsection{Recommendations for Future Modeling R\&D}

Developing improved temporal and spatial resolution methods is an active area of research among the four modeling teams included here. Moving forward, the teams have identified several areas of priority for future $\mathrm{R} \& \mathrm{D}$, including:

- More systematic study of the cost/benefit tradeoffs of increased resolution-The general understanding is that higher resolution leads to improved model results but also incurs additional computational burden. That tradeoff strongly depends on the methods and model used. More work is needed to better quantify and categorize the impact of both the resolution and method on model accuracy and computational cost. This necessarily requires developing and testing input data with greater resolution and/or scope, such as sub-hourly load and VRE time series data and/or multiple years of such time series data. Such experiments can help modelers better prioritize resolution tradeoffs and understand the scenario assumptions under which greater model resolutions matter most. 
- Understanding of how much resolution is needed for VRE deployment projections -VRE characteristics are generally better represented at higher resolution, but the marginal value of additional resolution will decrease as the resolution increases. The value of the additional resolution will also depend on the level of VRE penetration (e.g., a 100\% VRE study would need more resolution than a 50\% VRE study) A quantitative understanding of how much resolution is needed in making VRE deployment projections would allow modeling teams to ensure they have a sufficiently robust representation of VRE characteristics.

- Metrics to quantify if and how much results improve with increased resolution or selection methodology - In order to assess the cost/benefit tradeoffs of the resolution and method choices, metrics need to be developed to provide equitable comparison and benchmarking of these choices and the model used. These standards would ideally also serve to validate new or improved methods. The metrics can also be used to inform decisions as to whether methods should be directly incorporated within a model or if methods should be used to parameterize existing model formulations.

- Methods that can capture chronology for representing energy storage, unit commitment, and dispatch - The modeling techniques described here generally ignore many chronological issues that are important for a number of operational constraints. There is a need for methods that either can incorporate chronology directly into the models or can parameterize the chronological aspects in a way that the current methodologies can represent those chronological aspects.

\subsection{Resource Adequacy}

One of the key factors that long-term models must consider is whether there is sufficient capacity to maintain system reliability. Resource adequacy refers to the need to have enough available resources to meet anticipated demand while accounting for a reasonable number of contingencies. Today's utilities and regulatory bodies typically measure resource adequacy using a planning reserve margin. Details of planning reserve margin calculations and definitions vary by organization, but in general the planning reserve margin represents the ratio of available capacity divided by the expected peak demand, and it is expressed as a percentage value over $100 \%$. For example, if a region expects to have $12 \mathrm{GW}$ of available capacity and has a $10-\mathrm{GW}$ peak, the planning reserve margin would be $20 \%$. Reference planning reserve levels range from $10 \%$ to $20 \%$ (NERC 2017 ) and are typically designed around a loss-of-load probability, such as one day of lost load per 10 years of operation. Nearly all regions in the United States and Canada currently have a higher planning reserve margin than the NERC reference levels (see Figure 7). The actual process of determining an appropriate planning reserve margin for a region includes a mix of technical analysis, economic analysis, and regulatory interactions. 


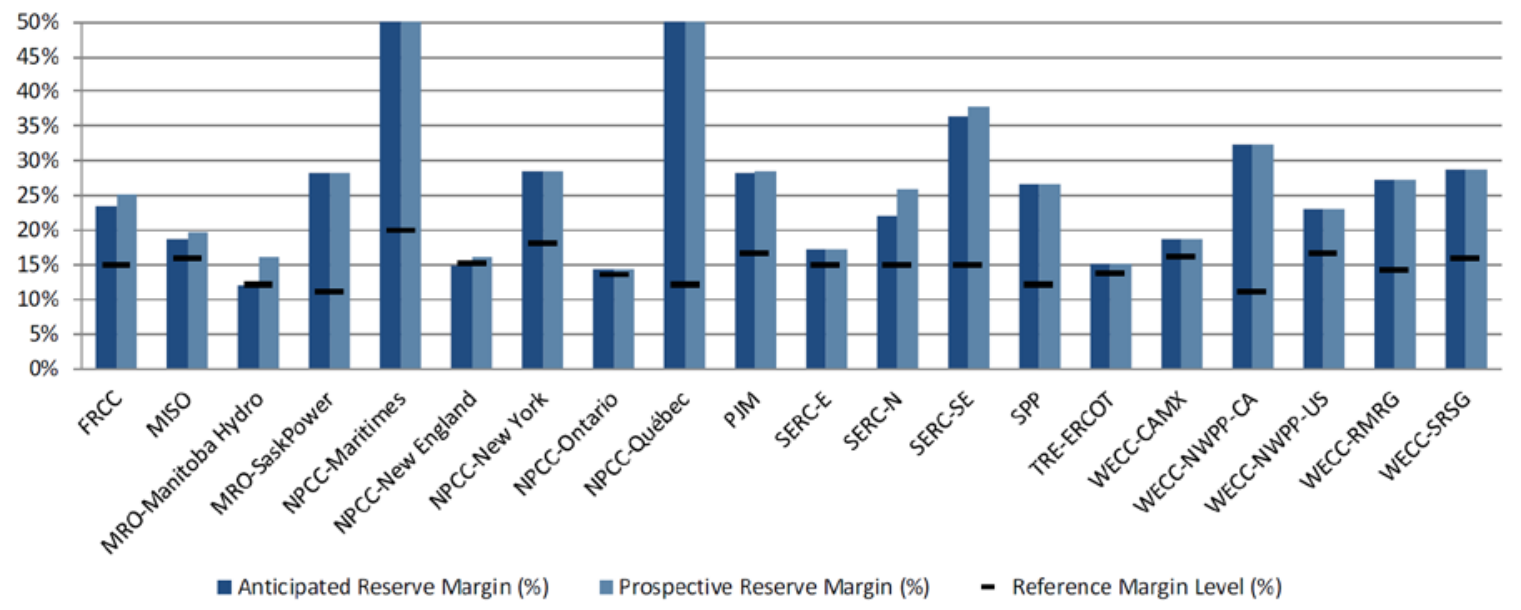

Figure 7. Reserve margins for each NERC assessment area (NERC 2017)

Capacity expansion models face two primary difficulties when representing resource adequacy. The first difficulty lies in determining the availability of VRE resources for meeting peak demand, or in other words, the contribution of a VRE generator toward the planning reserve margin. ${ }^{20}$ For example, how much can system operators rely on a wind or PV plant to be producing energy during peak demand periods? This contribution has typically been referred to as capacity value or capacity credit. The second difficulty lies in determining the level of resource adequacy that is sufficient. As shown in Figure 7, current reserve margins are generally higher (and sometimes much higher) than the reference reserve margin. Requiring too much capacity can result in a more expensive, overbuilt system, while too little capacity can result in expensive loss-of-load events. ${ }^{21}$ We discuss these challenges in detail below.

\subsubsection{VRE Contributions to Resource Adequacy}

Several methods have been developed to try to address the first difficulty of representing VRE generators' contribution toward resource adequacy. The methods used by the four capacity expansion models considered in this work are summarized in Table 7. Three of the four models assess contributions of both conventional and VRE capacity toward the NERC reference reserve margins, while US-REGEN uses a different methodology that derates the conventional capacity based on a calculated availability factor (see EPRI 2017, Section 2.3.3) and applies that derated capacity to the peak demand. Specifically for VRE capacity contributions, all of the models rely on more detailed underlying data, such as hourly wind or solar data. These data are then summarized outside the model optimization algorithm (see Section 3.1) and incorporated into the optimization in order to allow the model to make appropriate investment decisions that will result in systems with sufficient capacity. Though the algorithms and data requirements differ

\footnotetext{
${ }^{20}$ Conventional generators have long been a major part of the power system and do not rely on variable resources such as wind or sunlight, so their contribution toward resource adequacy is generally well understood and more easily represented.

${ }^{21}$ The CEMs in this work do not model loss-of-load events. Rather, they require a certain amount of resource adequacy and assume the level of resource adequacy is sufficient to meet required reliability levels. For this reason, it is important that the resource adequacy levels are appropriately represented in CEMs.
} 
among models, they generally calculate the anticipated generation from VRE resources during periods of peak net demand. ${ }^{22}$

Table 7. Summary of How Conventional and VRE Capacity Contribute to Resource Adequacy for the Four Models

\begin{tabular}{|c|c|c|c|c|}
\hline Model & $\begin{array}{l}\text { Resource Adequacy } \\
\text { Requirement }\end{array}$ & $\begin{array}{l}\text { Conventional Capacity } \\
\text { Contribution to } \\
\text { Resource Adequacy }\end{array}$ & $\begin{array}{l}\text { VRE Capacity } \\
\text { Contribution to } \\
\text { Resource Adequacy }\end{array}$ & $\begin{array}{l}\text { VRE Data Used } \\
\text { for Resource } \\
\text { Adequacy } \\
\text { Calculations }\end{array}$ \\
\hline IPM & $\begin{array}{l}\text { Planning reserve } \\
\text { margin based on } \\
\text { NERC reference } \\
\text { levels }\end{array}$ & $\begin{array}{l}\text { Installed net } \\
\text { summer capacity }\end{array}$ & $\begin{array}{l}\text { Specified exogenously } \\
\text { based on NEMS } \\
\text { capacity value outputs } \\
\text { scaled by difference } \\
\text { between IPM and } \\
\text { NEMS capacity factors }\end{array}$ & $\begin{array}{l}\text { Seasonal } \\
\text { generation } \\
\text { profiles }\end{array}$ \\
\hline NEMS & $\begin{array}{l}\text { Planning reserve } \\
\text { margin based on } \\
\text { NERC reference } \\
\text { levels }\end{array}$ & $\begin{array}{l}\text { Installed net } \\
\text { summer capacity }\end{array}$ & $\begin{array}{l}\text { Statistical method that } \\
\text { accounts for spatial and } \\
\text { temporal correlation of } \\
\text { wind/solar resources } \\
\text { within a region }\end{array}$ & $\begin{array}{l}\text { Average daily } \\
\text { generation by } \\
\text { month profiles }\end{array}$ \\
\hline ReEDS & $\begin{array}{l}\text { Planning reserve } \\
\text { margin based on } \\
\text { NERC reference } \\
\text { levels }\end{array}$ & $\begin{array}{l}\text { Installed net } \\
\text { summer capacity }\end{array}$ & $\begin{array}{l}\text { Average capacity factor } \\
\text { during the highest } 100 \\
\text { net load hours }\end{array}$ & $\begin{array}{l}\text { Hourly data from } \\
2006 \text { for load and } \\
\text { PV; hourly typical } \\
\text { meteorological } \\
\text { year data for } \\
\text { wind }\end{array}$ \\
\hline $\begin{array}{l}\text { US- } \\
\text { REGEN }\end{array}$ & $\begin{array}{l}\text { No reserve margin- } \\
\text { capacity derated } \\
\text { to account for } \\
\text { contingencies }\end{array}$ & $\begin{array}{l}\text { Installed net summer } \\
\text { capacity derated using } \\
\text { availability factors }\end{array}$ & $\begin{array}{l}\text { Capacity factor during } \\
\text { time slice with peak } \\
\text { net load }\end{array}$ & $\begin{array}{l}\text { Hourly data from } \\
2010 \text { for load, } \\
\text { PV, and wind }\end{array}$ \\
\hline
\end{tabular}

The lack of a metric for assessing whether a model is getting things "right" is one of the challenges of capturing VRE contributions. The general trends for the capacity value of VRE are well understood, namely, that wind has a low capacity value that does not change dramatically with penetration and that PV begins with a high capacity value that declines rapidly with penetration. The capacity value trends can be compared across models (see Figure 8) to ensure they are well behaved. In addition the capacity expansion model results have often been checked against more detailed models to ensure the systems they project do not drop load (Mai et al. 2012; Jorgensen, Mai, and Brinkman 2017; Bistline 2017), but there is no way to conclusively prove that the systems will meet the reliability targets anticipated by the reserve margins or availability factors. The comparison against the more detailed models, however, can reveal shortcomings of methodologies that can lead to improved methodologies. As a result of these challenges, modeling VRE contribution toward resource adequacy is still an active area of research (Frew et al. 2017), and all four modeling teams have identified areas in which they wish to improve their VRE representation for resource adequacy.

${ }^{22}$ Net demand is total demand minus VRE generation. 

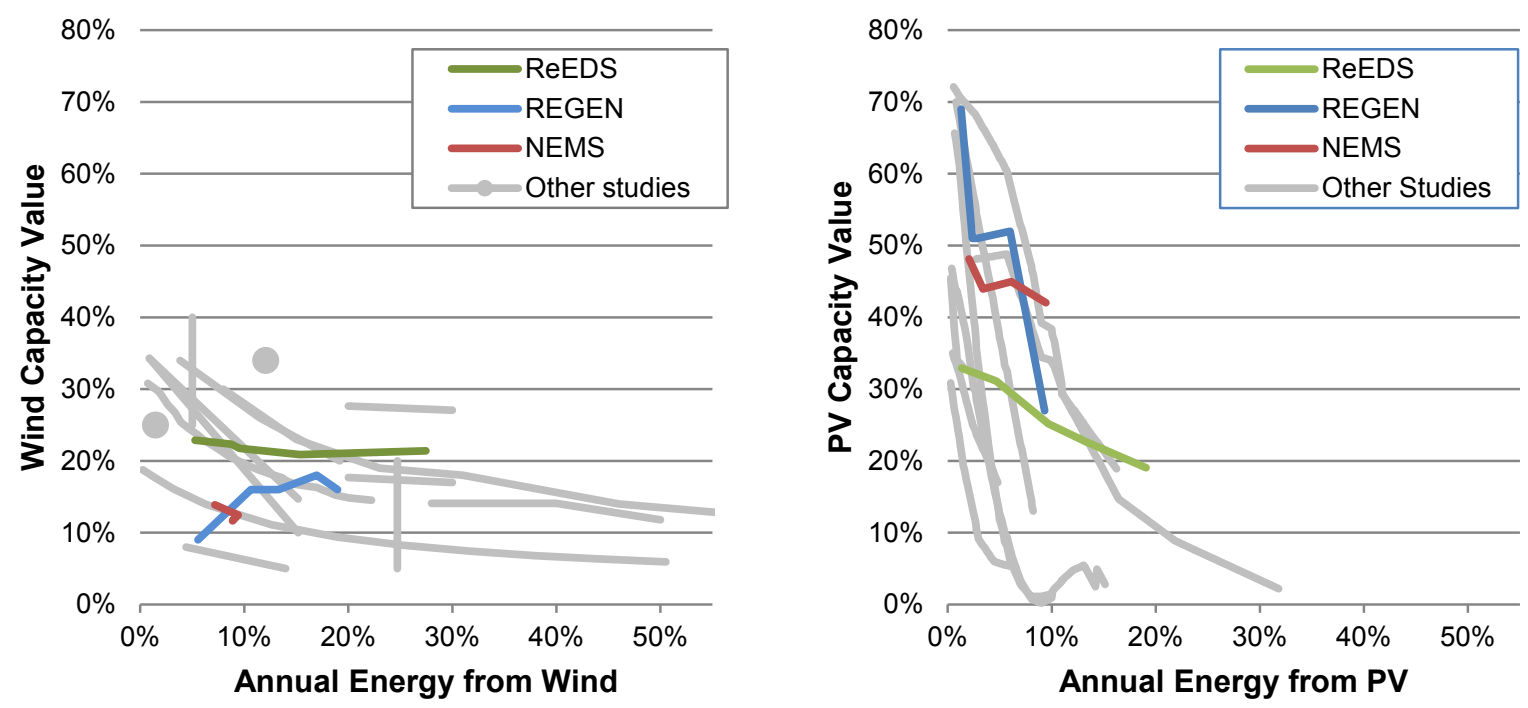

Figure 8. Capacity value for wind (left) and PV (right) as a function of PV and wind penetration

"Other studies" are from Holttinen et al. (2016) for wind and Mills and Wiser (2012), Denholm and Hummon (2012), and Jorgenson, Denholm, and Mehos (2014) for PV

One specific challenge for representing the capacity value of VRE in long-term planning models is data (Gami, Sioshansi, and Denholm 2017). Planning models are projecting new builds of VRE generators, and thus, no historical data exist for how well the generation from these new builds will align with peak demand. Furthermore, because weather patterns change from year to year, it is not clear how multiple years of data should be used to determine VRE capacity value. For example, if a wind generator has a low output in year one during the peak hour and a high output in year two during the peak hour, should the generator have a low value, high value, or some combination of the two values for its capacity value contribution? Because of processing time and computing resource limitations, CEMs tend to look at a deterministic year for load and VRE availability rather than use a probabilistic approach or one that considers multiple yearsworth of data. Additional years of high-resolution data are available for wind and PV, but lack of high-resolution load data has been a shortcoming that has made it difficult to expand the models to use multiple years of data.

\subsubsection{Determination of the Resource Adequacy Level}

Although VRE treatment for resource adequacy has received significant attention, significantly less research has been directed toward determining the appropriate resource adequacy level of future power systems. Reference case or business-as-usual scenarios in capacity expansion models regularly include increasing shares of VRE (Cole et al. 2016; EIA 2017a; Bistline et al. 2017). And, the models are often employed to analyze scenarios with significant changes, such as carbon reduction scenarios (EPA 2015a), rapid electrification (Steinberg et al. 2017), alternate oil and gas resource and technology projections (EIA 2017a), and deep decarbonization scenarios (Bistline and Chesnaye 2017). The systems projected in even the reference scenarios can be substantially different from today's system. Because the models use current or historical data to determine resource adequacy (based on NERC's reference-level reserve margins or on historical plant availability), it is not clear that these metrics will still be sufficient for future power systems that in some cases are vastly different from today's system. 


\subsubsection{Other Resource Adequacy Challenges}

In addition to the challenges laid out above, there are other important factors for addressing resource adequacy in long-term planning models. As can be seen in Table 7, the models have different methods for treating conventional capacity, and these differences can end up being significant when aggregated over the entire U.S. power system. Moreover, the primary drivers for the need for new capacity are retirements of existing generators and growth in peak demand. The four models have very different methods for treating existing plant retirements, which results in vastly different needs for new capacity (see Figure 9). Peak demand in the four models is typically scaled according to projected electricity demand growth, where all four models rely on the integrated NEMS model to project how annual electricity demand will change over time. Additionally, changes in end-use demands are challenging to capture, especially with respect to how they might alter load change and impact peak demand requirements. In many analyses, load shapes are assumed to be constant over time. ${ }^{23}$ All these factors influence how much capacity is needed and therefore the relative economics of new VRE generators.

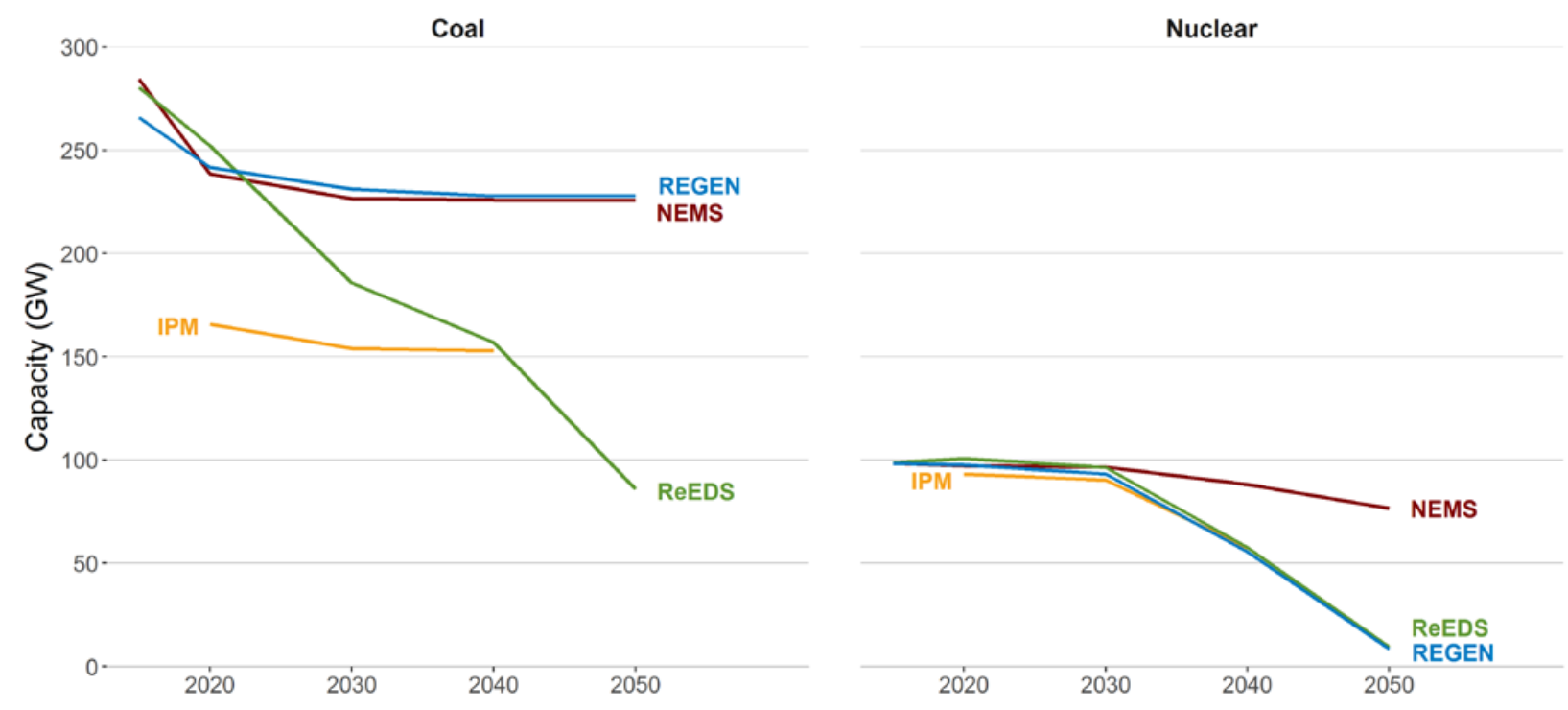

Figure 9. Coal capacity (left) and nuclear capacity (right) in the model's reference case scenarios

Finally, although all four models allow capacity to be shared between regions, little work has been done to understand the load diversity between regions in order to assess the benefits and limitations of sharing power between regions. This factor becomes especially important when considering very long-distance transmission lines that might connect regions with different time zones and therefore very different load shapes.

\footnotetext{
${ }^{23}$ NEMS includes a demand-side module, so the extent to which load shapes are updated over time depend on the assumptions and methods included in this module.
} 


\subsubsection{Recommendations for Future Modeling R\&D}

Although significant progress has been made for representing resource adequacy, there is still substantial need for increased understanding and methodologies. The key R\&D recommendations we identified with respect to resource adequacy include:

- Understand how accurate VRE capacity value estimates need to be-Capacity value of VRE is often discussed as an important element to capture in long-term planning models, but the impact of underestimating or overestimating the capacity value has not been quantified. Relatedly, the methodologies used by planning models for VRE capacity value estimates are similar but vary considerably in their data and computational requirements, and to our knowledge, no one has performed a comprehensive comparison and validation of the data and techniques to understand the various tradeoffs of the methodologies.

- Understand how much capacity is needed, especially for higher-penetration VRE futuresModels typically rely on NERC reference reserve margins or historical data to specify required capacity needs, but the current power system exceeds those recommended levels. Improved understanding of historical reserve margin levels and what drives those levels can inform how resource adequacy requirements are made for long-term planning scenarios. Additionally, there might be value in incorporating more fundamental reliability metrics (e.g., loss-of-load probabilities) within the planning models.

- Improve VRE and load time series data-Models typically rely on a single year of simulated data that might not capture inter-annual weather patterns, load shapes, or less-common events. Multi-year data sets could potentially lead to resource adequacy estimates that are more robust. Additionally, validating or improving simulated data based on historical measured data can reduce or remove shortcomings associated with using simulated data for long-term projections.

- Improve data and methods for estimating retirements - Retirements represent a major driver for new capacity needs, but they are challenging to estimate within models. Cost data for current generators is difficult to obtain, and therefore methodologies are often built to accommodate the limited data that are available. Methodologies that can apply non-cost data, such as utilization or contract data, might effectively supplement the limited cost data. Any improvements to the accuracy or coverage of existing cost data sets will improve retirement estimates.

\subsection{Economics of Energy Production}

Because capacity expansion models are typically least-cost optimization models (see Table 2), the relative economics of the various technologies are a primary driver of model results. Because of current policies, such as renewable portfolio standards and the sometimes long lead-time to build new plants, the economics play a lesser role in the short-term ${ }^{24}$ but are a more significant driver over the long term.

\footnotetext{
${ }^{24}$ Economics do impact near-term decisions, but in many cases, the decision to build a new plant in the near term has already been made and the economics inside the model therefore do not impact whether that plant comes online.
} 
At low penetration, nearly all VRE generation can be utilized. However, as the VRE penetration increases, the potential for curtailment, which is the intentional reduction in generation from VRE generators when generation exceeds load, can substantially increase (Denholm and Margolis 2016; Denholm, Clark, and O'Connell 2016). VRE curtailment can result from insufficient transmission capacity to export surplus power to neighboring regions, the inability to store surplus energy, and/or the inability to ramp down generation from committed thermal units (Bird, Cochran, and Wang 2014; Fink et al. 2009).

The specific representation of VRE curtailment varies across models, but the methods are all essentially doing an accounting to determine the amount of VRE generation that cannot be absorbed by the system. Assumptions with respect to transmission limitations, storage, and thermal unit minimum generation levels drive the ability of the system to absorb more VRE, and those assumptions certainly vary from one model to another. Comparing the curtailment outputs among models can be especially challenging because actual curtailment rates tend to be low $(<5 \%)$ even at fairly significant penetration levels. Instead, curtailment calculations within capacity expansion models are usually compared against curtailment estimates from an hourly chronological model. For example, DOE (2012), Mai et al. (2012), and Jorgensen, Mai, and Brinkman (2017) compared ReEDS curtailment estimates against those of an hourly production cost model. And, these comparisons have shown that the current methodologies capture curtailment fairly well for the specific scenarios that were examined. However, it is unclear whether these methodologies will remain robust across a wider range of scenarios, such as those with significant amounts of inflexible load, restricted transmission expansion, or high penetrations of new storage capacity. Additionally, the impacts of unit commitment and ramping restrictions are typically ignored in the capacity expansion models, and it is unclear when or how frequently their exclusion can have an impact on model results.

If VRE curtailment is not represented in a capacity expansion model, that model is likely to overestimate the value of VRE technologies. Given that today's VRE penetration levels are still relatively low, the exclusion of curtailment is unlikely to significantly impact near-term modeling results. ${ }^{25}$ However, because VRE curtailment increases as VRE penetration increases, medium- and long-term projections are likely to be significantly impacted. Solar PV economics are especially impacted by curtailment because PV production is typically more strongly autocorrelated than production from wind plants, which results in a steep increase in curtailment rate as PV penetration increases (Denholm and Margolis 2016). Figure 10 shows the impact of not including curtailment within the NEMS model reference scenario for this exercise. Excluding curtailment leads to increased solar penetration as well decreased gas, wind, and coal generation. Without the curtailment represented in the model, utility-scale PV generation nearly doubles. This scenario is approaching 20\% VRE penetration, so the impact of curtailment in higher penetration scenarios would be even more significant.

\footnotetext{
${ }^{25}$ Regionally, the exclusion of curtailment might be impactful. For example, California experienced solar curtailments in the first half of 2017, and ERCOT had high levels of wind curtailment before expanding transmission and implementing new operational practices.
} 

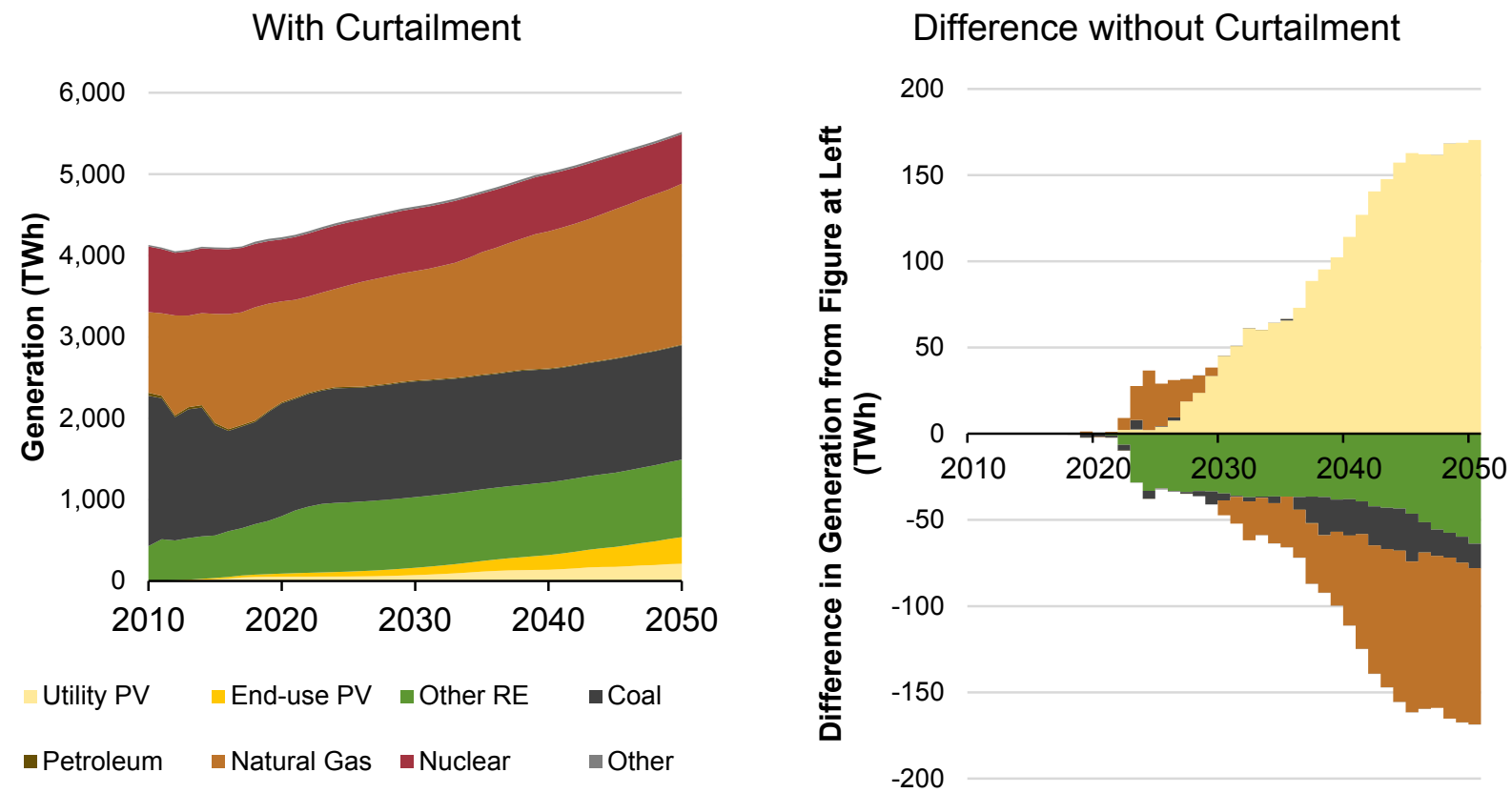

Figure 10. NEMS generation mix in the reference case when curtailment is included (left) and the difference in generation when curtailment is not included (right)

Operating reserves needed for VRE integration are another aspect of VRE representation that can impact economics. Higher penetrations of VRE typically require a greater amount of operating reserves to account for short-term errors between VRE forecasted and actual generation. Sample scenarios using the NEMS model demonstrated this through adjusting the level of spinning reserve capacity required as a percentage of available operating VRE capacity in each timeslice. For low operating reserve requirements (where the VRE-specific spinning reserves contribution was at $25 \%$ of VRE available capacity or less), ${ }^{26}$ the impact on the capacity expansion solution was negligible. At higher requirements (where the VRE-specific reserves were at $50 \%$ of VRE available capacity or more), the impact became more pronounced.

Another major component of the economic competitiveness of VRE is the way in which financing is treated in the model. VRE technologies are capital-intensive technologies, meaning nearly all their cost is upfront capital cost associated with their construction and that their O\& $\mathrm{M}$ costs are relatively low. In contrast, fuel-burning technologies such as coal, natural gas, and biopower plants can have significant fuel costs that are spread over the lifetime of the plant. Because of the capital-intensive nature of VRE technologies, they are more strongly impacted by financing assumptions; lower financing costs can make them more competitive with fuel-burning generators, while higher financing costs can do the opposite. We found a range of financing assumptions across the four models (see Table 8), and we also found that measuring the quality of financing assumptions can be especially difficult, especially when considering that projections extend to 2050 or later.

\footnotetext{
${ }^{26}$ This operating reserve requirement is the fraction of the available VRE capacity in each time slice that must be matched with spinning reserves.
} 
Table 8. Financing Assumptions Used in the Four Models

\begin{tabular}{|c|c|c|c|c|c|c|}
\hline & $\begin{array}{l}\text { IPM: } \\
\text { Merchant }\end{array}$ & $\begin{array}{l}\text { IPM: } \\
\text { Utility }\end{array}$ & $\begin{array}{l}\text { IPM: } \\
\text { Overall }\end{array}$ & $\begin{array}{l}\text { NEMS } \\
\left(^{(A E O 2017)^{a}}\right.\end{array}$ & $\begin{array}{l}\text { US- } \\
\text { REGEN }\end{array}$ & ReEDS \\
\hline Debt Interest Rate & $5.30 \%$ & $2.50 \%$ & - & $3.7 \%$ & - & $5.4 \%$ \\
\hline Rate of Return on Equity & $10.10 \%$ & $5.30 \%$ & 一 & $8.2 \%$ & - & $10.2 \%$ \\
\hline WACC & $5.90 \%$ & $3.01 \%$ & $3.88 \%$ & $5.1 \%$ & $5 \%$ & $5.4 \%$ \\
\hline $\begin{array}{l}\text { Economic Evaluation } \\
\text { Period (years) }\end{array}$ & $20-40$ & $20-40$ & $20-40$ & 30 & $25-100$ & 20 \\
\hline
\end{tabular}

All percentage values are in real (as opposed to nominal) terms.

${ }^{\text {a }}$ Financing in NEMS varies over time; the values included here are the long-term financing values in the model.

The impact of varying financing assumptions on the levelized cost of electricity (LCOE) for a wind plant is shown in Figure 11. The four WACC levels from Table 8 are shown, along with a range of cost recovery periods from 20 years to 30 years. There is a difference of about $\$ 6 / \mathrm{MWh}$ across the WACC values (holding economic lifetime constant) and across economic lifetime values (holding WACC constant). ${ }^{27}$ A sample scenario using the ReEDS model showed that changing the economic lifetime of all generators from 20 years to 30 years led to a $33 \%$ increase in VRE capacity under reference scenario conditions.

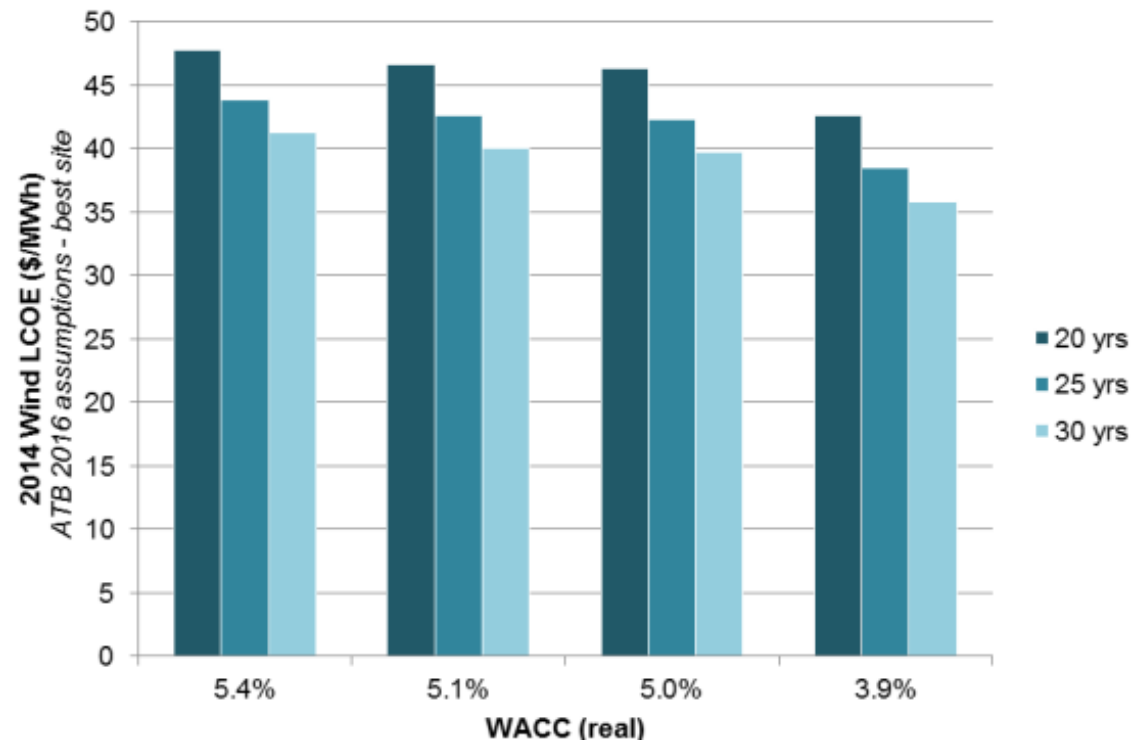

Figure 11. Impact of financing assumptions on the LCOE of a wind plant LCOE calculated using the 2016 Annual Technology Baseline (ATB) spreadsheet (NREL 2016).

\footnotetext{
${ }^{27}$ LCOE values are calculated using the 2016 Annual Technology Baseline spreadsheet (NREL 2016).
} 
The cost of connecting VRE resources to the grid is the final aspect of the economics of VRE that we considered in our CEM modeling workshops. VRE generators are often built in locations that are more remote and thus require some investment in the transmission system to move the VRE generation to a load center. This area of representing VRE transmission connection costs has received much less attention in the literature, with most of the published work relegated to model documentation. The methods used to represent these costs for the four models are summarized in Table 9. Interconnection values of $\$ 100 / \mathrm{kW}-200 / \mathrm{kW}$ represent approximately $5 \%-10 \%$ of the cost of a wind plant and approximately $5 \%-20 \%$ of the cost of a utility PV plant, so these values are not insignificant. Comparison of methods with actual historical builds and improved methods for identifying new VRE sites could lead to more robust methods and more confidence in transmission connection costs.

Table 9. Summary of Transmission Connection Costs for VRE Technologies

\begin{tabular}{|l|l|l|l|l|}
\hline & IPM $^{\mathrm{a}}$ & NEMS $^{\mathrm{a}}$ & ReEDS & US-REGEN \\
\hline Type of Cost & Multiplier & Multiplier & Adder & Adder \\
\hline Type of Values & Supply curve & Supply curve & Supply curve & Fixed value \\
\hline Technologies Included & Wind & Wind & Wind, PV, CSP & Wind, PV \\
\hline Typical Value & $\sim \$ 200 / \mathrm{kW}$ & $\sim \$ 200 / \mathrm{kW}$ & $\sim \$ 100 / \mathrm{kW}$ & $\$ 200 / \mathrm{kW}$ \\
\hline Typical Range of Values & $0-\$ 2,000 / \mathrm{kW}$ & $0-\$ 2,000 / \mathrm{kW}$ & $\$ 10-\$ 1,000 / \mathrm{kW}$ & $\$ 200 / \mathrm{kW}$ \\
\hline
\end{tabular}

${ }^{a}$ IPM and NEMS do not apply a separate interconnection value to new wind capacity but instead uses a range of multipliers to capture cost increases stemming from a variety of factors, including distance from existing transmission, site accessibility challenges, population proximity, and other factors. The capital cost multipliers for onshore wind add between $0 \%$ and $100 \%$ to the cost of a new wind plant.

\subsubsection{Recommendations for Future Modeling R\&D}

- More robust understanding of curtailment outside current system boundaries-Current methods for estimating VRE curtailment appear to be robust when compared with more detailed models, but that comparison has only been made for a small number of scenarios. Scenarios with significant changes in minimum generation levels from thermal plants, storage deployment, or demand-side technologies could challenge the curtailment methods that have already been developed.

- Improved methods for how financing assumptions are assigned to a technology_Financing can have significant impacts on model results, but the financing assumptions that should be used for a given technology are not well understood or represented in long-term planning models. Financing parameters such as interest rate and rate of return on equity might change over time and be especially difficult to set appropriately, but economic lifetimes can likely be well understood and represented in the modeling.

- Improved methods for capturing VRE transmission connection costs - Transmission connection costs can represent a significant fraction of the cost of a new plant, but it is unclear whether current methods are underestimating or overestimating those costs and how this might impact model results. 


\subsection{Other Considerations}

Although the workshops focused on the topics discussed above, a number of important ancillary topics arose. These ancillary topics were not discussed in detail, but we include them here for the sake of completeness in documenting workshop findings and because these topics deserve ample consideration for long-term planning $\mathrm{R} \& \mathrm{D}$.

- Methods for representing energy storage-There is considerable desire to consider low-cost storage or other similar scenarios in long-term planning models, but the methodologies and metrics for representing storage are not yet well defined. This is especially true for the interaction of VRE generators with storage technologies. Issues such as chronology, capacity value, and cost representation have yet to be addressed in most large-scale modeling frameworks.

- Improved methods for handling the demand-side-Energy efficiency, customer behavior, electric vehicles, and general energy electrification can significantly impact electricity demand, both in terms of total electricity demand as well as the shape of the load profile. Methods for understanding and projecting demand-side changes at a national scale within electricity-sector-only models are generally limited or are in their early stages of development.

- Assessment of importance of intraregional transmission for long-term planning decisionsAlthough many models capture the cost of building intraregional transmission to connect new generators to existing transmission, none of the four models represents transmission flows or limitations within a balancing area. It is not clear whether this is a minor assumption for the purpose of capacity expansion or it might significantly alter model results. Also, how this assumption might interact with selected spatial resolution is unknown.

- Metrics for assessing model behavior-Model behavior is often assessed based on expert opinion and/or other more detailed modeling tools. Metrics that can be used to more concretely measure and assess model behavior can accelerate model development and improve model utility. 


\section{Summary and Conclusions}

Capacity expansion models provide a useful tool for understanding how VRE interacts with and will influence the future power sector under a wide range of economic, technology, and policy conditions. However, because of the complexities associated with VRE and with long-term projections, considerable work remains to be done to improve the utility of these models. The four modeling teams involved in this comparison effort identified three key areas of active model enhancement to improve the VRE representation within these planning models: (1) spatial and temporal resolution, (2) resource adequacy, particularly the accounting method for VRE capacity, and (3) economics of energy production, with a focus on the impact of curtailment on VRE economics.

Both the temporal and spatial resolution choice and method employed in a model can significantly impact the results. In general we find that increased resolution leads to better representation of total system cost and of VRE characteristics, but it is unclear how much resolution is necessary to answer the questions asked of the model. Additionally, different questions might require different levels of resolution.

Curtailment and capacity value of VRE are two of the most significant system characteristics to represent in capacity expansion models. The existing methods for handling curtailment and capacity value of VRE are generally sufficient at capturing VRE economics under systems with low-tomoderate penetrations of VRE. However, these methods may not be sufficiently robust for futures that are vastly different from today, and improvements will likely be needed. At a minimum, increased understanding of high penetration VRE scenarios is needed to give increased confidence in model solutions that show significant evolution from today's system.

Other aspects of VRE (i.e., outside of curtailment and capacity value) do not generally have as wellestablished methods, but it is also unclear to what degree they ultimately matter for ensuring projected investment decisions are robust. For example, operating reserves, grid connection costs, and financing costs are typically represented, but the best methods for doing so are not well defined, and the impact of each is typically not well understood. Additionally, aspects that are typically not represented, such as unit commitment, are also poorly understood with respect to how they might impact investment decisions.

Across the four modeling teams that participated in our workshops, we found that most of the research and innovation with respect to capacity expansion models utilize "out-of-optimization" methodologies. In other words, new capabilities are developed using pre- or post-process innovations that allow the already large and complicated optimization problem not to grow in size as additional capabilities are added. We also found that the rapidly changing grid environment opens new challenges, especially with respect to modeling storage and demand-side technologies.

Through this multi-model exercise, we have identified several areas for future modeling research and development. These areas are included at the end of Sections 3.1.3, 3.2.4, 3.3.1, and 3.4. Finally, we found that a collective environment to share ideas across modeling teams has led to higher quality models and has bolstered individual model development, including many of the model enhancements and method comparisons highlighted in this report (see the appendix for a summary of model enhancements). We recommend collaboration across capacity expansion modeling teams, especially as the research and development areas described in this report are pursued. 


\section{References}

ABB. 2016. "E7 Capacity Expansion: Long-Term Resource Planning for Resource Planners and Portfolio Managers." http://new.abb.com/docs/librariesprovider139/default-documentlibrary/epm_capacity-expansion_jul16_web.pdf?sfvrsn=2.

Bird, L., J. Cochran, and X. Wang. 2014. "Wind and Solar Energy Curtailment: Experience and Practices in the United States.” NREL/TP-6A20-60983. National Renewable Energy Laboratory (NREL), Golden, CO. https://doi.org/10.2172/1126842.

Bistline, John. 2017. "Economic and Technical Challenges of Flexible Operations under LargeScale Variable Renewable Deployment.” Energy Economics 64 (Supplement C):363-72. https://doi.org/10.1016/j.eneco.2017.04.012.

Bistline, John, and Francisco de la Chesnaye. 2017. "Banking on Banking: Does 'When' Flexibility Mask the Costs of Stringent Climate Policy?" Climatic Change, August, 1-14. https://doi.org/10.1007/s10584-017-2053-6.

Bistline, John, D. Shawhan, Geoffrey Blanford, Francisco de la Chesnaye, B. Mao, Nidhi Santen, and R. Zimmerman. 2017. "Systems Analysis in Electric Power Sector Modeling: Evaluating Model Complexity for Long-Range Planning.” 3002011365. Palo Alto, CA: Electric Power Research Institute.

Blanford, Geoffrey, James Merrick John Bistline, and David Young. 2016. "Simulating Annual Variation in Load, Wind, and Solar by Representative Hour Selection.” 3002008653. Palo Alto, CA: Electric Power Research Institute. https://www.epri.com/\#/pages/product/000000003002008653/.

Cole, Wesley, Trieu Mai, Jeffrey Logan, Daniel Steinberg, James McCall, James Richards, Benjamin Sigrin, and Gian Porro. 2016. "2016 Standard Scenarios Report: A U.S. Electricity Sector Outlook.” NREL/TP-6A20-66939. Golden, CO: National Renewable Energy Laboratory. http://www.nrel.gov/docs/fy17osti/66939.pdf.

Denholm, Paul, Kara Clark, and Matt O'Connell. 2016. 'On the Path to SunShot: Emerging Issues and Challenges in Integrating High Levels of Solar into the Electrical Generation and Transmission System." Golden, CO: National Renewable Energy Laboratory. http://www.osti.gov/scitech/biblio/1253978.

Denholm, Paul, and Marissa Hummon. 2012. "Simulating the Value of Concentrating Solar Power with Thermal Energy Storage in a Production Cost Model." NREL/TP-6A2056731. Golden, CO: National Renewable Energy Laboratory. https://www.nrel.gov/docs/fy13osti/56731.pdf.

Denholm, Paul, and Robert Margolis. 2016. "Energy Storage Requirements for Achieving 50\% Solar Photovoltaic Energy Penetration in California.” NREL/TP-6A20-66595. Golden, CO: National Renewable Energy Laboratory. http://www.nrel.gov/docs/fy16osti/66595.pdf.

DOE. 2012. "SunShot Vision Study.” DOE/GO-102012-3037. Washington, D.C.: U.S. Department of Energy. http://www.nrel.gov/docs/fy12osti/47927.pdfDOE/GO-1020123037.

Edelenbosch, O. Y., K. Kermeli, W. Crijns-Graus, E. Worrell, R. Bibas, B. Fais, S. Fujimori, P. Kyle, F. Sano, and D. P. van Vuuren. n.d. "Comparing Projections of Industrial Energy Demand and Greenhouse Gas Emissions in Long-Term Energy Models." Energy. Accessed January 26, 2017. https://doi.org/10.1016/j.energy.2017.01.017.

EIA. 2017a. “Annual Energy Outlook 2017.” DOE/EIA-0383(2017). Washington, D.C.: U.S. DOE Energy Information Administration. 
. 2017b. "The Electricity Market Module of the National Energy Modeling System:

Model Documentation 2016.” Washington, D.C.: U.S. Energy Information

Administration.

https:/www.eia.gov/outlooks/aeo/nems/documentation/electricity/pdf/m068(2016).pdf.

EPA. 2013. "Documentation for EPA Base Case v.5.13 Using the Integrated Planning Model."

450R13002. Washington, D.C.: U.S. Environmental Protection Agency.

https:/www.epa.gov/sites/production/files/2015-

07/documents/documentation_for_epa_base_case_v.5.13_using_the_integrated_planning -model.pdf.

- 2015a. "Carbon Pollution Emission Guidelines for Existing Stationary Sources: Electric Utility Generating Units.” 2015. http:/www.epa.gov/airquality/cpp/cpp-final-rule.pdf. . 2015b. "EPA Base Case v.5.15 Using IPM.” U.S. Environmental Protection Agency. https:/www.epa.gov/sites/production/files/2015-

08/documents/epa_base_case_v.5.15_incremental_documentation_august_2015.pdf.

EPRI. 2017. “US-REGEN Model Documentation.” EPRI Technical Update \#3002010956. Palo Alto, CA: Electric Power Research Institute.

Eurek, Kelly, Wesley Cole, David A. Bielen, Nate Blair, Stuart Cohen, Bethany Frew, Jonathan Ho, Venkat Krishnan, Trieu Mai, and Daniel Steinberg. 2016. "Regional Energy

Deployment System (ReEDS) Model Documentation: Version 2016." NREL/TP-6A2067067. Golden, CO: National Renewable Energy Laboratory.

http://www.nrel.gov/docs/fy17osti/67067.pdf.

Fink, Sari, C. Mudd, K. Porter, and Brett Morgenstern. 2009. "Wind Energy Curtailment Case Studies.” NREL Subcontract Report, NREL/SR-550 46716. http://www.nrel.gov/docs/fy10osti/46716.pdf.

Frew, Bethany A., Wesley J. Cole, Yinong Sun, Trieu T. Mai, and James Richards. 2017. "8760-

Based Method for Representing Variable Generation Capacity Value in Capacity Expansion Models: Preprint." NREL/CP-6A20-68869. National Renewable Energy Laboratory (NREL), Golden, CO (United States).

https://www.osti.gov/scitech/biblio/1375305-based-method-representing-variablegeneration-capacity-value-capacity-expansion-models-preprint.

Gami, D., R. Sioshansi, and P. Denholm. 2017. "Data Challenges in Estimating the Capacity Value of Solar Photovoltaics.” IEEE Journal of Photovoltaics 7 (4):1065-73. https://doi.org/10.1109/JPHOTOV.2017.2695328.

Getman, Dan, Anthony Lopez, Trieu Mai, and Mark Dyson. 2015. "Methodology for Clustering High-Resolution Spatiotemporal Solar Resource Data.” NREL/TP-6A20-63148. Golden, CO: National Renewable Energy Laboratory. https://www.nrel.gov/docs/fy15osti/63148.pdf.

Hale, Elaine, Brady Stoll, and Trieu Mai. 2016. "Capturing the Impact of Storage and Other Flexible Technologies on Electric System Planning.” NREL/TP-6A20-65726. Golden, CO: National Renewable Energy Laboratory. http://www.nrel.gov/docs/fy16osti/65726.pdf.

Holttinen, Hannele, Juha Kiviluoma, Alain Forcione, Michael Milligan, Charles J. Smith, Jody Dillon, Jan Dobschinski, et al. 2016. "Design and Operation of Power Systems with Large Amounts of Wind Power: Final Summary Report, Iea Wind Task 25, Phase Three 2012-2014.” Espoo, Finland: VTT Technical Research Centre of Finland Ltd. https://www.ieawind.org/task_25/PDF/T268.pdf. 
IEA. 2015. "World Energy Model Documentation.” Paris, France: Organisation for Economic Co-operation and Development (OECD), International Energy Agency (IEA).

Intergovernmental Panel on Climate Change (IPCC). 2015. Climate Change 2014: Mitigation of Climate Change: Working Group III Contribution to the IPCC Fifth Assessment Report. Cambridge: Cambridge University Press. /core/books/climate-change-2014-mitigationof-climate-change/81F2F8D8D234727D153EC10D428A2E6D.

Jorgensen, Jennie, Trieu Mai, and Greg Brinkman. 2017. "Reducing Wind Curtailment Through Transmission Expansion in a Wind Vision Future.” NREL/TP--6A20-67240. Golden, CO: National Renewable Energy Laboratory. https://doi.org/10.2172/1339078.

Jorgenson, Jennie, Paul Denholm, and Mark Mehos. 2014. "Estimating the Value of UtilityScale Solar Technologies in California Under a 40\% Renewable Portfolio Standard." NREL/TP-6A20-61685. Golden, CO: National Renewable Energy Laboratory. https://doi.org/10.2172/1134134.

Krishnan, Venkat, and Wesley Cole. 2016. "Evaluating the Value of High Spatial Resolution in National Capacity Expansion Models Using Reeds.” Poster NREL/PO-6A20-66786. Golden, CO: National Renewable Energy Laboratory. http://www.nrel.gov/docs/fy16osti/66002.pdf.

Kroposki, B., B. Johnson, Y. Zhang, V. Gevorgian, P. Denholm, B. M. Hodge, and B. Hannegan. 2017. "Achieving a 100\% Renewable Grid: Operating Electric Power Systems with Extremely High Levels of Variable Renewable Energy." IEEE Power and Energy Magazine 15 (2):61-73. https://doi.org/10.1109/MPE.2016.2637122.

Mai, Trieu, Clayton Barrows, Anthony Lopez, Elaine Hale, Mark Dyson, and Kelly Eurek. 2015. "Implications of Model Structure and Detail for Utility Planning: Scenario Case Studies Using the Resource Planning Model.” NREL/TP--6A20-63972. National Renewable Energy Lab. (NREL), Golden, CO (United States).

https://www.osti.gov/scitech/biblio/1334388-implications-model-structure-detail-utilityplanning-scenario-case-studies-using-resource-planning-model.

Mai, Trieu, John Bistline, Yinong Sun, Cara Marcy, Christopher Namovicz, David Young, and Wesley Cole. forthcoming. "Insights into the Future of Variable Renewable Energy: A Multi-Model Perspective of the U.S. Electricity System."

Mai, Trieu, R. Wiser, D. Sandor, G. Brinkman, G. Heath, P. Denholm, D. J. Hostick, N. Darghouth, A. Schlosser, and K. Strzepek. 2012. "Exploration of High-Penetration Renewable Electricity Futures. Vol. 1 of Renewable Electricity Futures Study." NREL/TP-6A20-52409-1. Golden, CO: National Renewable Energy Laboratory.

Milligan, Michael, Bethany A. Frew, Aaron Bloom, Erik Ela, Audun Botterud, Aaron Townsend, and Todd Levin. 2016. "Wholesale Electricity Market Design with Increasing Levels of Renewable Generation: Revenue Sufficiency and Long-Term Reliability." The Electricity Journal 29 (2):26-38. https://doi.org/10.1016/j.tej.2016.02.005.

Mills, Andrew, and Ryan Wiser. 2012. "Changes in the Economic Value of Variable Generation at High Penetration Levels: A Pilot Case Study of California." LBNL-5445E. Berkeley, CA: Lawrence Berkely National Laboratory. http:/emp.lbl.gov/sites/all/files/lbnl5445e.pdf.

Nahmmacher, Paul, Eva Schmid, Lion Hirth, and Brigitte Knopf. 2016. "Carpe Diem: A Novel Approach to Select Representative Days for Long-Term Power System Modeling." Energy 112 (Supplement C):430-42. https://doi.org/10.1016/j.energy.2016.06.081. 
Nelson, James, Josiah Johnston, Ana Mileva, Matthias Fripp, Ian Hoffman, Autumn PetrosGood, Christian Blanco, and Daniel M. Kammen. 2012. "High-Resolution Modeling of the Western North American Power System Demonstrates Low-Cost and Low-Carbon Futures." Energy Policy 43 (Supplement C):436-47. https://doi.org/10.1016/j.enpol.2012.01.031.

NERC. 2017. "2017 Summer Reliability Assessment." http://www.nerc.com/pa/RAPA/ra/Reliability\%20Assessments\%20DL/2017\%20Summer $\% 20$ Assessment.pdf.

NREL. 2016. “2016 Annual Technology Baseline.” Golden, CO: National Renewable Energy Laboratory. http://www.nrel.gov/analysis/data_tech_baseline.html.

—. 2017. "2017 Annual Technology Baseline." Golden, CO: National Renewable Energy Laboratory. http://www.nrel.gov/analysis/data tech baseline.html.

Pietzcker, Robert C., Falko Ueckerdt, Samuel Carrara, Harmen Sytze de Boer, Jacques Després, Shinichiro Fujimori, Nils Johnson, et al. n.d. "System Integration of Wind and Solar Power in Integrated Assessment Models: A Cross-Model Evaluation of New Approaches." Energy Economics. Accessed January 25, 2017. https://doi.org/10.1016/j.eneco.2016.11.018.

Pietzcker, Robert Carl, Daniel Stetter, Susanne Manger, and Gunnar Luderer. 2014. "Using the Sun to Decarbonize the Power Sector: The Economic Potential of Photovoltaics and Concentrating Solar Power." Applied Energy 135 (December):704-20. https://doi.org/10.1016/j.apenergy.2014.08.011.

Santen, Nidhi, John Bistline, Geoffrey Blanford, and Francisco de la Chesnaye. 2017. "Electric Power Sector Systems Analysis: A Review of the Recent Literature and Capabilities of Selected Capacity Planning Tools." 3002011102. Palo Alto, CA: Electric Power Research Institute. https://www.epri.com/\#/pages/summary/000000003002011102/.

Sigrin, B., P. Sullivan, E. Ibanez, and R. Margolis. 2014. "Representation of the Solar Capacity Value in the Reeds Capacity Expansion Model: Preprint." NREL/CP-6A20-62015. National Renewable Energy Laboratory (NREL), Golden, CO. https://www.osti.gov/scitech/biblio/1150799-representation-solar-capacity-value-reedscapacity-expansion-model-preprint.

Steinberg, Daniel, Dave Bielen, Josh Eichman, Kelly Eurek, Jeff Logan, Trieu Mai, Colin McMillan, Andrew Parker, Laura Vimmerstedt, and Eric Wilson. 2017. "Electrification and Decarbonization: Exploring U.S. Energy Use and Greenhouse Gas Emissions in Scenarios with Widespread Electrification and Power Sector Decarbonization." NREL/TP--6A20-68214. Golden, CO: National Renewable Energy Laboratory. https://doi.org/10.2172/1372620.

Sun, Yinong, and Wesley J. Cole. 2017. "Transmission Flow Methodologies: Approximate DC Flow vs. Pipe Flow Along AC Lines.” NREL/PR-6A20-68929. Golden, CO: National Renewable Energy Laboratory. https://www.nrel.gov/docs/fy17osti/68929.pdf.

Ueckerdt, Falko, Lion Hirth, Gunnar Luderer, and Ottmar Edenhofer. 2013. "System LCOE: What Are the Costs of Variable Renewables?” Energy 63 (Supplement C):61-75. https://doi.org/10.1016/j.energy.2013.10.072.

WECC. 2013. "2013 Interconnection-Wide Plan Tools and Models." https://www.wecc.biz/Reliability/2013Plan_ToolsandModels.docx 


\section{Appendix. Summary of Model Enhancements}

One purpose of the two CEM modeling workshops was to stimulate improvements and examine assumptions in each the models, especially as they relate to VRE representation. Each of the modeling teams identified and/or incorporated improvements and analyses between the two workshops, and a summary of those is provided here.

\section{IPM}

The EPA IPM team is planning to implement several improvements to VRE representation in the upcoming release of IPM v6. The most significant improvements include implementation of 8760 hourly generation profiles, increased time slices targeting more resolution during baseload hours, time-of-day differentiation, an additional winter season to better capture variability in wind performance, VRE spur line costs integrated with the capital costs of new units, and a new methodology to impose declining capacity value on new VRE resources.

\section{NEMS}

EIA has scheduled several modeling updates focused on improving representation of the value and impact of VRE generation on the grid. Between AEO 2016 and the results shared in this report, EIA updates to NEMS included changing the representation of residential solar PV from a simple cash flow model to a statistical model, capturing a more detailed representation of the end-use solar PV generation on net demand, and modeling solar PV and wind curtailments. In addition, for AEO 2018, other modeling updates include integrating a four-hour energy storage technology and modifying the regional solar resource to reflect a supply curve rather than an average value. In addition to model updates, EIA conducted a number of model experiments, including an analysis of the curtailment algorithm and a review of the spinning reserve algorithm.

\section{ReEDS}

The most significant change to the ReEDS model was the incorporation of a new VRE capacity value calculation methodology that uses hourly data to assess the contribution of existing and potential new VRE generators toward the resource adequacy requirement. The methodology was discussed briefly in Section 3.1.1, and details are reported by Frew et al. (2017). In addition, the ReEDS team assessed the difference between a pipe-flow transmission representation and a DCpower-flow representation (Sun and Cole 2017), and it did model runs comparing different financing assumptions Finally, the incremental value used for calculating marginal VRE capacity values and curtailment rates was examined to see how it impacts model results.

\section{US-REGEN}

The US-REGEN team conducted experiments to explore the impacts of spatial and temporal resolution on model outputs. Detailed information about these analyses, results, and implications for modeling can be found in Bistline et al. (2017). The team also added a wider variety of utility-scale PV technologies, and the model now allows investments in fixed-tilt, single-axis tracking, and double-axis tracking technologies. In addition, EPRI updated its representations of operating reserves, planning reserves, and energy storage to illustrate potential effects of alternate formulations and parameters. 